\title{
Weak Vestibular Response in Persistent Developmental Stuttering: Implications for Own Voice Identification
}

\section{Max Gattie ${ }^{*}$, Elena Lieven ${ }^{2}$, Karolina Kluk ${ }^{1}$}

${ }^{1}$ Manchester Centre for Audiology \& Deafness (ManCAD), University of Manchester, Oxford Road, Manchester, M13 9PL, UK

${ }^{2}$ LuCiD (the ESRC International Centre for Language and Communicative Development), University of Manchester, Oxford Road, Manchester, M13 9PL, UK

\section{* Correspondence:}

Corresponding Author

max.gattie@manchester.ac.uk

Keywords: Stuttering1, vestibular, efference copy3, speech-motor control4, own voice identification ${ }_{5}$, speech perception 6 , auditory scene analysis 7 , speech-induced suppression 8.

\begin{abstract}
Speech-motor and psycholinguistic models employ feedback control from an auditory stream corresponding to own voice. Such models underspecify how own voice is identified. It is proposed that own voice is identified through coincidence detection between the neural firing rates arising from deflection of cochlear and vestibular mechanoreceptors by the sound and vibration generated during vocalisation. The coincidence detection is proposed to differ in people who stutter. In an update to the approach-avoidance conflict model of Sheehan $(1953,1975)$ instances of stuttering are proposed to coincide with uncertainty over an ongoing speech act. Discussion covers speech-induced suppression, auditory scene analysis, and theories of mental content.
\end{abstract}

\section{Introduction}

Speech-motor and psycholinguistic models describe a feedforward system in which articulatory muscles receive coordinated nerve impulses with sufficient detail to generate speech sounds (e.g. Hickok \& Poeppel, 2007; Levelt et al., 1999; Tourville \& Guenther, 2011). Typically they employ feedback control as a check for error (Helmholtz, 1886; von Holst \& Mittelstädt, 1950; Fairbanks, 1954). Predictive feedback control avoids instability due to timing delay by checking for sensory error against a forward model of the speech-motor plan (see review in Parrell \& Houde, 2019). Errors checked for might include articulatory malfunction, or mismatch between spoken and intended message - the nature of the error checked for will vary, depending on the nature of the model.

Such models underspecify how an auditory stream corresponding to own voice is identified (i.e. an auditory stream defined as per Bregman, 1990). A typical requirement is that a mental representation of expected auditory consequences is referred to, or is already identical with, an auditory target map (O'Callaghan, 2015). The question arises of how such reference is managed in the opposite direction how an auditory target map for own voice is created from ambient sound and vibration. 
Greater understanding of own voice identification could improve speech-motor and psycholinguistic models. For example, previously overlooked activity in the auditory brainstem and periphery may explain otherwise intractable difficulties in understanding the cerebral and cerebellar activity accompanying speech and language. Such an approach is taken in the current article. A hypothesis is formulated for own voice identification. The hypothesis is then developed to provide an account of stuttering, a DSM-V diagnosis characterised by involuntary prolongations and repetitions during speech.

The article will proceed as follows. Section 2 will describe the hypothesis of own voice identification. Section 3 will build on the hypothesis of section 2 to present a novel account of stuttering, REMATCH (Reflexivity and Communicative Mismatch). Section 4 will provide discussion of themes arising from sections 2 and 3. In this way, the article will extend from a biophysical account of own voice identification, to a psychosocial account of interpersonal communication. It will progress from audiology, to speech-motor theory, to psycholinguistics and social psychology.

Hypothesis formulation follows inference to the best explanation (Lipton, 2004). Best explanation arguments are mutually supportive. In other words, if one has a best explanation argument of $T$, and one has a best explanation argument of $D$, it follows that one has a best explanation argument of $(T+D)$. This pertains even if $D$ is partially reliant on $T$. This system (sometimes referred to as abduction) differs from, for example, multiplicative combination of probabilities in which the combined probability is lower than either of its constituents. Refuting a best explanation argument requires presentation of a better explanation. The discussion in section 4 will summarise the scope of the best explanation argument. To aid that discussion, hypotheses will be presented following the Methodology of Scientific Research Programmes described by Lakatos (1970). This refers to a "hard core" of (generally unfalsifiable) hypotheses, along with a "protective belt" of testable auxiliary hypotheses. Distinction will also be made between the two kinds of causal explanation described by Botterill (2010). Process explanations are of how something happens, whereas contrastive explanations are of why something happens. These two kinds of explanation interact as understanding of causation is acquired and enhanced.

\section{Hypothesis of Own Voice Identification}

\subsection{Explanatory target}

Own voice identification is a specific instance of the cocktail party problem (Bee \& Micheyl, 2008), an outstanding issue in auditory scene analysis in which there is no principled basis for discrimination in a multi-talker scenario. It is an example of an ill-posed problem (Hadamard 1902, 1923; Poggio \& Koch, $1985)$, sometimes referred to as an inverse problem, in which there is no mathematically unique solution.

\subsection{Candidate explanations}

There is no prior research offering a basis by which an own voice auditory stream is specifically distinguished from ambient sound and vibration (Shamma \& Micheyl, 2010; Remez \& Thomas, 2013; Bronkhorst, 2015). The most closely related literature emphasises the importance of body conducted vibration during own speech (von Békésy, 1949; Maurer \& Landis, 1990; Pörschmann, 2000; Sohmer \& Freeman, 2001; Shuster \& Durrant, 2003; Reinfeldt et al., 2010; Meekings et al., 2015) or else describes 
self talk and private speech through a Vygotskian developmental perspective (e.g. Fernyhough \& Russell, 1997; Atencio \& Montero, 2009; Lupyan \& Swingley, 2012).

There is also a large body of work about the role of own voice in speech monitoring systems (e.g. Postma, 2000; Buschbaum, 2001; Ozdemir et al., 2007; Huettig \& Hartsuiker, 2010; Nozari et al., 2011; Lind et al., 2014; Acheson \& Hagoort, 2014; Kröger et al., 2016) or sensory-motor integration (e.g. Jürgens, 2002; Kaplan et al., 2008; Rosa et al., 2008; Zheng et al., 2010; Hickok et al., 2011; Behroozmand et al., 2015; Houde et al., 2015). This literature takes as a starting point that own voice has already been identified as an ascending auditory stream. It therefore does not address the current explanatory target. Literature concerning sensory-motor integration, and in particular the hypothesis of speech-induced suppression, will be discussed in section 2.4.1.

\subsection{A Novel Hypothesis of Own Voice Identification}

\subsubsection{Introduction}

The nature of the speech auditory brainstem response (BinKhamis et al., 2019) suggests that neural activity corresponding to identification of own voice could occur in the auditory brainstem. The auditory brainstem is innervated through the VIII cranial nerve, from bipolar ganglion cells which interface with mechanoreceptors of the inner ear. Neural activity corresponding to own voice could occur at the earliest within the bipolar ganglion cells of the ear itself.

Inner ear structure is common across mammals, consisting of an osseous labyrinth lined with sensory epithelium, and with several chambers. One of the chambers is the cochlea, a coiled structure containing mechanoreceptors which are deflected by ambient sound frequencies ranging from $20 \mathrm{~Hz}-20,000 \mathrm{~Hz}$ in humans (Manley \& Gummer, 2017). Other chambers comprise the vestibular system. These chambers include semicircular canals, in which mechanoreceptors are deflected by changes in angular velocity. There are also gravitoinertial otoliths, arranged such that mechanoreceptors are deflected by changes in linear velocity, and with resting state deflection corresponding to head orientation (Goldberg, 2012).

The traditional discrimination just described, of cochlear and vestibular chambers into hearing and equilibrial functions, is misleading (Tait, 1932). As for other vertebrates, mammalian otolithic receptors are deflected by vibration as well as by changes in body velocity or orientation relative to a fixed gravitational field. The vestibular system in mammals responds to vibrational frequencies up to $1,000 \mathrm{~Hz}$, and may phase lock to higher frequencies (Curthoys et al., 2019).

Vestibular sensitivity is considerably greater to vibrations conducted through the body $(B C)$ than to sound waves in air ( $A C)$. Electrophysiological studies show that when human responses of vestibular origin are referenced to a $60 \mathrm{dBA}$ sound level typical of conversational speech, $A C$ thresholds are $10 \mathrm{~dB}$ above baseline and BC thresholds 25 dB below baseline (McNerney \& Burkard, 2011; Welgampola, Rosengren, Halmagyi \& Colebatch, 2003). The act of speaking will deflect vestibular mechanoreceptors in humans (Todd, Rosegren \& Colebatch, 2008; Curthoys, 2017; Curthoys et al., 2019).

\subsubsection{Concurrency Hypothesis}

The core hypothesis is that own voice is identified as an auditory stream through coincidence detection between vestibular and cochlear afferents. This will henceforth be referred to as the Concurrency Hypothesis.

The Concurrency Hypothesis describes a biologically grounded mechanism. The biological grounding is that there are two sets of mechanoreceptors for own voice. Figure 1 gives an overview of relevant details. Sound and vibrational energy deflecting sterocilia in cochlear hair cells corresponds to own voice 
mixed with ambient environmental sounds. Concurrently, vibrational energy deflecting stereocilia in vestibular hair cells corresponds to own voice in isolation. Comparison of nerve impulses arising from cochlear and vestibular mechanoreceptors therefore provides a principled distinction between self and environment.

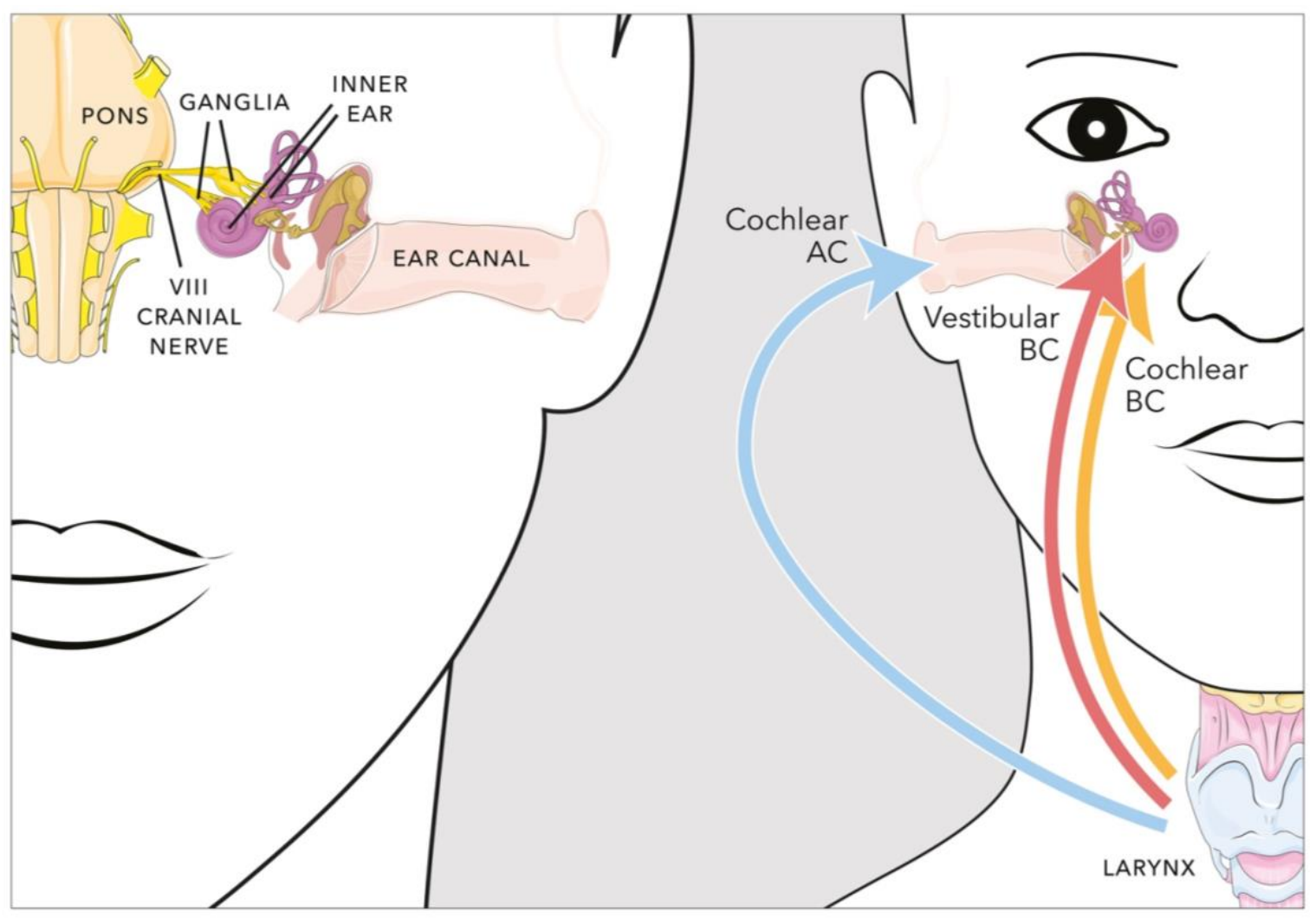

Figure 1: Parameters affecting sound and vibration detection in the human ear. In vivo measurements are difficult, and estimates here are derived from primary sources where possible. For general background on sound source perception, see Yost et al. (2008); for hair cells see Eatock et al. (2006); for voice production see Titze (1994); and for propagation of sound and vibration see Fahy \& Thompson (2015).

Left hand side: Anatomical parameters. Dendrons of bipolar ganglion cells terminate on sensory epithelial hair cells in the inner ear. Axons from the ganglia project or branch through the VIII cranial nerve to nuclei of the pons and medulla, and (for some axons from vestibular ganglia) the cerebellum. Sensory hair cells fire continuously, with changes in firing rate following deflections due to sound, vibration and movement. Changes in firing rate will in turn modify long-term potentiation of brainstem and cerebellar nerve cells.

Right hand side: Acoustic and vibrational parameters. During vocalisation, sound and vibration en ergy originates predominantly at the larynx (and occasionally higher in the vocal tract; Titze, 1994). Energy propagates via two routes to each ear: air conduction (AC) through air surrounding the head, or body conduction $(B C)$ through the neck and head. The inner ear includes cochlear and vestibular sensory hair cells. Sounds are perceived when $\mathrm{AC}$ and $\mathrm{BC}$ stimulation above hearing threshold (by definition zero dB HL or higher) deflects stereocilia in cochlear hair cells, opening mechanically gated ion channels which set off a chain of activity culminating in release of neurotransmitters, which in turn will raise potentials in dendrites of ganglion cells belonging to the VIII cranial nerve. Deflection of stereocilia in vestibular hair cells requires a considerably higher stimulus level than that for sterocilia in cochlear hair cells. Welgampola et al. (2003) established electrophysiological vestibular thresholds (VEMPs) at sound 
levels, as defined at the cochlea, of $31 \mathrm{~dB}$ HL for BC stimulation, and $87 \mathrm{~dB}$ HL for AC stimulation. Even after adjusting for temporal integration with the brief duration stimuli used in electrophysiological testing, $A C$ vestibular thresholds are $10 \mathrm{~dB}$ above, and $B C$ vestibular thresholds $25 \mathrm{~dB}$ below, the 60 dBA sound level typical of conversational speech (McNerney \& Burkard, 2011). Thus, own voice is either not detected or is very weakly detected via an $A C$ vestibular route. Whereas, unless using alaryngeal speech such as whispering, own voice will consistently be detected by a BC vestibular route. This $B C$ vestibular audition of own voice will persist even if $A C$ and $B C$ cochlear audition of own voice is masked.

(C) Adapted by Max Gattie from illustrations by Servier Medical Art, https://smart.servier.com. Creative Commons 3.0 licence.

159

160

161

Estimating arrival times for own voice stimuli at the inner ear requires consideration of propagation routes (figure 2). Air-conducted (AC) sound can be direct (dAC) or reflected ( $\mathrm{AC}$ ), whereas bodyconducted $(\mathrm{BC})$ vibration can be considered as direct only. Table 1 estimates arrival time at the inner ear at approximately $0.5 \mathrm{~ms}$ after vocalisation for both $\mathrm{dAC}$ sound and $\mathrm{BC}$ vibration. At $60 \mathrm{dBA}$ stimulus levels (typical of vocalisation) BC vibration deflects both cochlear and vestibular mechanoreceptors (McNerney \& Burkard, 2011; Welgampola, Rosengren, Halmagyi \& Colebatch, 2003). Table 1 compares the propagation timings. Binaural coincidence detection across cochlear and vestibular mechanoreceptors, based on $\mathrm{dAC}$ sound and $\mathrm{BC}$ vibration, would identify own voice.
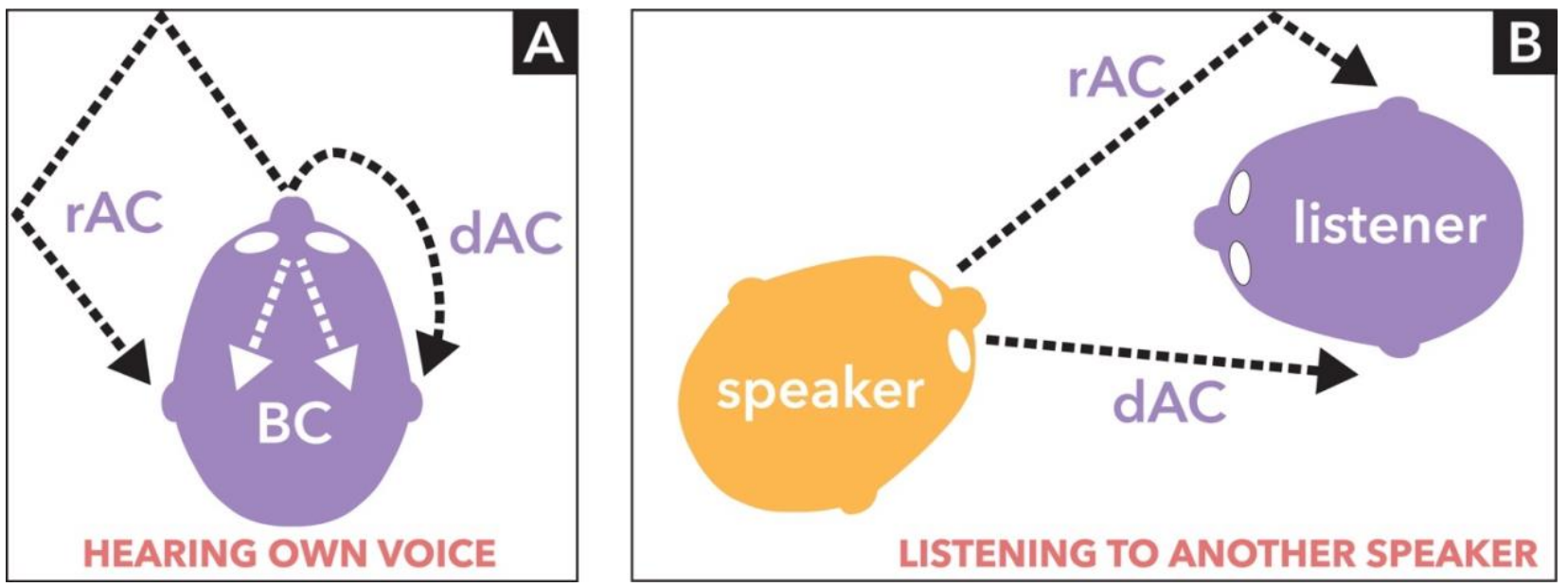

Figure 2: Sound and vibration routes to the ear. Propagation routes are difficult to measure in vivo, and estimates here are derived from primary sources where possible. For general background on sound source perception, see Yost et al. (2008); and for propagation of sound and vibration see Fahy \& Thompson (2015).

Air-conducted sound is split between reflected ( $\mathrm{rAC}$ ) and direct (dAC) routes (Cabrera et al., 2009; Traer \& McDermott, 2016). These are shown in a simplified version. The rAC consists of many environmental reflections with comb filtering (frequencies attenuated or reinforced due to phase differences) as sound energy reaches the ear (Yadav et al., 2012; Arend et al., 2017). The many possible routes for $\mathrm{AAC}$ reflect the relationship between body and environment. If reflections of reflections are present (e.g. standing waves inside a room) rAC becomes reverberation. The dAC route is transmitted directly through the air around the speaker's head. This route includes body reflection, such as that from the shoulders. There is just one form of dAC, which will tend to be stable over the short-term (unless it is windy) and medium-term (unless the head rotates relative to the torso). Conditions in which dAC is unstable tend to also be ones in which conversation is difficult. 
(A) Transmission time estimates are based on human head dimensions, and will vary according to skull size and individual physiology. When hearing own voice, dAC sound is transmitted at $340 \mathrm{~m} / \mathrm{s}$ and so will reach the ear in about $0.5 \mathrm{~ms}$. Body conduction (BC) is through bone or soft tissue (Sohmer, 2017; Chordekar et al., 2018). Propagation routes are complex and frequency dependent, will differ between individuals, and have a nature not fully determined in vivo. However, the complexity of propagation routes will be stable in adults, changing only gradually with head composition and body profile across the lifespan. A propagation rate of $300 \mathrm{~m} / \mathrm{s}$ is likely in humans (Hotehama \& Nakagawa, 2012). If so, BC transmission time can be estimated as similar to the $0.5 \mathrm{~ms}$ for dAC. A distance of $1.5 \mathrm{~cm}$ between cochlear and vestibular hair cells (Ekdale, 2013) gives propagation time for vibration across the inner ear as $\mathbf{0 . 0 5} \mathbf{~ m s}$. This becomes an upper limit for arrival time difference from a laryngeal source, meaning $B C$ arrival time is coincident to less than $0.05 \mathrm{~ms}$ for vestibular and cochlear mechanoreceptors. Routes to the ear for rAC will typically take 2-20 ms (depending on environmental parameters), and will be considerably less stable than for $\mathrm{dAC}$ or $\mathrm{BC}$ given that the environment, and the position of the head relative to surroundings, can be expected to change continuously.

(B) When listening to another speaker, dAC sound energy travelling a direct route between interlocutors is heard first. Energy travelling the longer, indirect route of rAC trails dAC slightly (e.g. by 5-10 ms, depending on environment). Thus, changes in firing rates of inner ear hair cells due to a typical $200 \mathrm{~ms} \mathrm{CV}$ speech syllable travelling dAC and rAC routes will be spread over a further 2-50 ms or more, depending on proximity of interlocuters and environmental reflections. This overlaps with the time window for the Haas, or precedence, effect - a psychoacoustic phenomenon in which sounds separated by less than about 50 ms are perceptually integrated, with longer delays perceived as echo (Haas, 1951; Wallach et al., 1949). Overwhelmingly, dAC and rAC will have different presentations at each ear, along with comb filtering interactions, such that source localisation is via stereo combination following the duplex theory of Rayleigh (1907). There is in principle a confound for sound sources occupying the "cone of confusion" (a set of points equidistant from each ear) in symmetrical environments or those, like an anechoic chamber, with minimal rAC. In practice such a situation is so unlikely to be sustained that it would not normally have developmental impact (but see Cody et al., 1996). For animals with a pinna, filtering effects of the pinna reduce localisation inaccuracy for sources within the cone of confusion (Musican \& Butler, 1984).

\section{(C) Creative Commons 4.0 licence.}

\begin{tabular}{|l|l|l|l|l|}
\hline \multicolumn{2}{|l}{ HEARING OWN VOICE: Routes to each ear } \\
\hline Route & $\begin{array}{l}\text { Sensory } \\
\text { organ }\end{array}$ & $\begin{array}{l}\text { Arrival time } \\
\text { after } \\
\text { vocalisation }\end{array}$ & $\begin{array}{l}\text { Interaural } \\
\text { arrival time } \\
\text { and intensity }\end{array}$ & Comment \\
\hline BC & $\begin{array}{l}\text { Vestibular } \\
\text { system }\end{array}$ & $\sim 0.5 \mathrm{~ms}$ & $\begin{array}{l}\text { Identical } \\
\text { (assumes } \\
\text { body } \\
\text { symmetry) }\end{array}$ & $\begin{array}{l}\text { Insensitive to environmental variation. BC attenuation and } \\
\text { filtering are consistent in the short- and medium-term, with only } \\
\text { small and gradual long-term changes which follow head } \\
\text { composition and body profile across the lifespan. }\end{array}$ \\
\hline BC & $\begin{array}{l}\text { Cochlea } \\
\text { Sy }\end{array}$ & $0.5 \mathrm{~ms}$ &
\end{tabular}


HEARING OWN VOICE: Routes to each ear

\begin{tabular}{|c|c|c|c|c|}
\hline Route & $\begin{array}{l}\text { Sensory } \\
\text { organ }\end{array}$ & $\begin{array}{l}\text { Arrival time } \\
\text { after } \\
\text { vocalisation }\end{array}$ & $\begin{array}{l}\text { Interaural } \\
\text { arrival time } \\
\text { and intensity }\end{array}$ & Comment \\
\hline $\mathrm{dAC}$ & Cochlea & $\sim 0.5 \mathrm{~ms}$ & $\begin{array}{l}\text { Near } \\
\text { identical (can } \\
\text { vary with } \\
\text { head } \\
\text { orientation } \\
\text { and air } \\
\text { turbulence) }\end{array}$ & $\begin{array}{l}\text { During vocalisation, dAC and BC contributions are approximately } \\
\text { equal at the cochlea (von Békésy, 1949; Pörschmann, 2000; } \\
\text { Reinfeldt et al., 2010). Some spectral variation (e.g. nasal } \\
\text { phonemes more prominent over BC) due to filtering differences } \\
\text { between air and body. Recordings of own speech (capturing } \\
\text { predominantly dAC) are often found by the speaker to differ from } \\
\text { what is heard while speaking (a mixture of BC and dAC, with some } \\
\text { rAC). }\end{array}$ \\
\hline rAC & Cochlea & $\begin{array}{l}\text { typically 2- } \\
50 \mathrm{~ms}\end{array}$ & Different & $\begin{array}{l}\text { Arrives within 2-50 ms (or longer, depending on environment) of } \\
\mathrm{d} A C \text { sound and } B C \text { vibration. Less sonic/vibrational energy than } \\
\text { the } \mathrm{dAC} / \mathrm{BC} \text { mixture. Delay relative to } \mathrm{dAC} / \mathrm{BC} \text { creates comb } \\
\text { filtering. Delays of } \mathrm{rAC} \text { above } \sim 50 \mathrm{~ms} \text { are experienced } \\
\text { psychoacoustically as an echo; delays of } \mathrm{rAC} \text { below } \sim 50 \mathrm{~ms} \text { are } \\
\text { psychoacoustically fused with } \mathrm{dAC} / \mathrm{BC} \text { as in the Haas or } \\
\text { precedence effect. }\end{array}$ \\
\hline
\end{tabular}

Table 1: Sound and vibrational energy is transmitted to each ear through body conduction (BC) and direct and reflected air conduction ( $\mathrm{AAC} / \mathrm{rAC}$ ), and can deflect two sets of mechanoreceptors in each inner ear. At stimulus levels typical of own voice, vestibular mechanoreceptors are only deflected by BC vibration.

Groups of neurons having response properties supporting coincidence detection on the millisecond timescales required for the hypothesised own voice identification mechanism can be found in the cochlear nucleus and superior olivary complex. Review of brainstem neurons can be found in Golding \& Oertel (2012) and review of vestibular inputs to the cochlear nucleus in Newlands et al. (2003) or Smith (2012). Figure 3 shows a sagittal view of brain areas innervated by the inner ear, and figure 4 shows cortical areas with connectivity to the vestibular system alongside areas important for speech and language. The cochlear nucleus and superior olivary complex comprise initial stages in a subcortical chain referred to as the ascending auditory pathway (Irvine, 1992). Changes in firing rates within brainstem neurons which correspond to the hypothesised coincidence detection could in turn be expected to change activity at higher stages of the ascending auditory pathway, including inputs to the cortex. Such activity could be interpreted as an auditory stream which identifies own voice. 


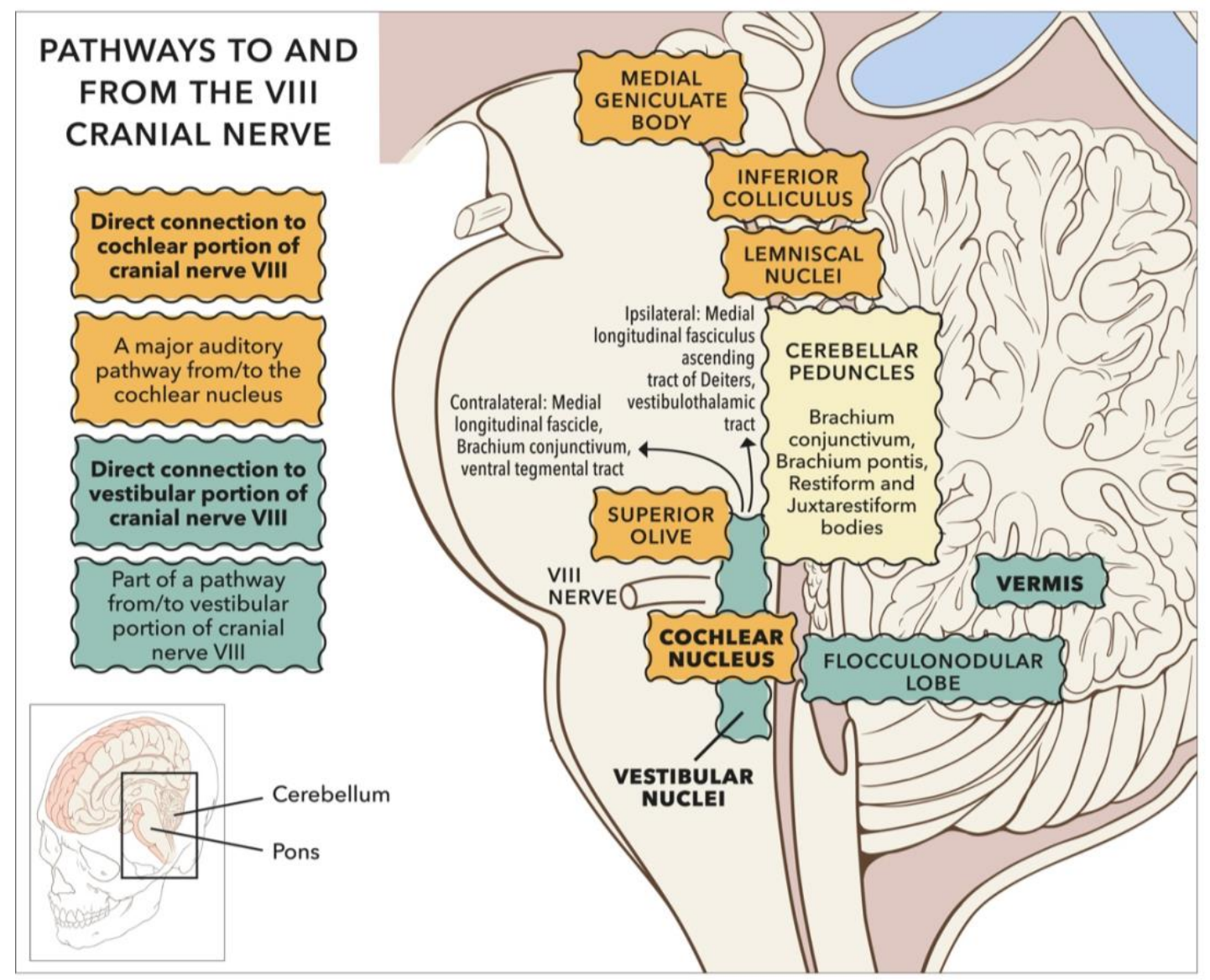

Figure 3: Sagittal view of subcortical pathways to and from the VIII cranial nerve. Whilst the auditory pathway ascending from the cochlear nucleus is relatively well established (Irvine, 1992), pathways to and from vestibular nuclei remain under investigation (Pierrot-Deseilligny \& Tilikete, 2008; Zwergal et al., 2009). Investigation is largely using animal models. Projections to vestibular cortex via the thalamus have been established in humans through clinical observation and lesion studies (Conrad et al., 2014; Hitier et al., 2014; Wijesinghe et al., 2015). Vestibular nuclei also project down the spine (not shown).

(c) Portions of this figure were adapted from illustrations by Patrick J. Lynch, http://patricklynch.net/. Creative Commons 2.5 licence. 


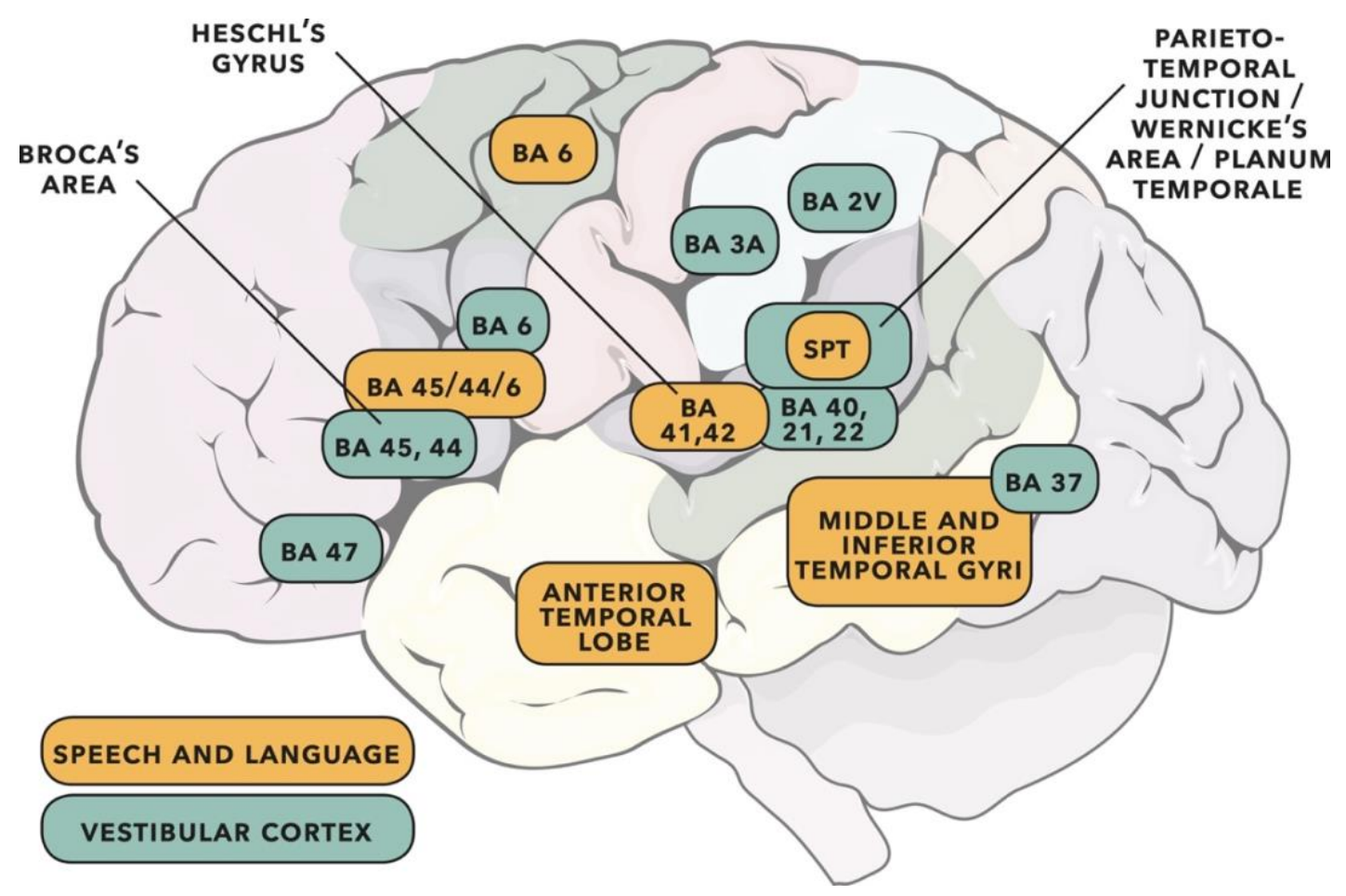

Figure 4: Cortical areas important for speech and language (adapted from the dual-stream model of Hickok \& Poeppel, 2007) shown with vestibular cortical areas identified in cats, monkeys and humans (adapted from Ventre-Dominey, 2014; see also Frank \& Greenlee, 2018). Cortical activity following vestibular input has wide interpretation (e.g. see reviews of cognition in Hitier et al., 2014, and auditory/rhythm/timing in Todd \& Lee, 2015). Some of the vestibular areas identified will be predominantly related to gravitoinertial function (see discussion in Ferrè \& Haggard, 2020). Numbers are Brodmann areas - see primary literature for more exact location detail. Spt is the Sylvian parietotemporal region proposed by Hickok \& Poeppel (2007) as a sensorimotor integration area. Vestibular sites in humans have been identified as such when direct electrical stimulation of the cortex gives rise to gravitoinertial illusion. When vestibular sites are identified within BA 21 (lateral temporal lobe) or BA 22 (Wernicke's area), auditory illusion is found to accompany gravitoinertial illusion (Kahane et al., 2003; Fenoy et al., 2006).

(C) Portions of this illustration were adapted from Servier Medical Art, https://smart.servier.com. Creative Commons 3.0 licence.

\subsubsection{Explanatory Power}

As a process explanation, the Concurrency Hypothesis provides a detailed account of how own voice is identified. The proposed involvement of particular types of brainstem neurons (e.g. octopus cells in the cochlear nucleus, or bipolar principal cells of the medial superior olive) generates testable auxiliary hypotheses (see discussion in sections 2.4 and 3.4). Whereas the existence of an own voice auditory stream, which is identified through coincidence detection between vestibular and cochlear afferents, is the core hypothesis.

There is also a contrastive explanation of why own voice is identified in the way described by the Concurrency Hypothesis. The contrastive explanation addresses evolutionary and philosophical considerations. The Concurrency Hypothesis as described so far is specific to mammals. However, the Concurrency Hypothesis could be extended to all terrestrial and amphibious vertebrates if the basilar papilla is considered in place of the cochlea; to fish if the lagena is considered; and in principle to any 
animal which produces sound and vibration, and has two or more sets of sensory receptors capable of detecting sound and vibration. See species surveys in Suthers, Tecumseh Fitch, Fay \& Popper (2016) and Pollack, Mason, Popper \& Fay (2019).

The prospect of such a wide taxonomic application for the Concurrency Hypothesis suggests a provenance early in evolution. This in turn prompts reconsideration of the role of the inner ear. The Concurrency Hypothesis provides a principled distinction between self (identification of own voice) and environment (reflection of own voice from surroundings). Such a distinction has importance for cognitive science and philosophy of mind (Wilson \& Foglia, 2017). For example, in a representational theory of mind the distinction between self and environment is integral to content determination (Pitt, 2020).

290

The basis for the self-environment distinction in the Concurrency Hypothesis is the presence of two sets of mechanoreceptors in the ear. One set of mechanoreceptors detects own voice in isolation, the other detects own voice mixed with ambient sound, including reflection of own voice. This is dissimilar to other modalities. For example, the visual analogy would be identification of one's own hand. However, photoreceptors do not collect sufficient information to identify one's own hand from light waves incident on the retina. Such identification would be possible following multisensory integration, but this is also the case for audition (e.g. as in the combination of audition with proprioception during vocalisation).

As such, audition might be the only modality within which self and environment can be distinguished. If so, multisensory integrations including audition could underlie self-environment distinction for modalities other than audition. Evolution of any such dependency would have to create phenotypes sufficiently robust to account for self-environment distinction when hearing ability is absent. Further consideration of such matters is beyond the scope of this article, but would follow discussions of heritability and innateness such as those in Griffiths (2020), Godfrey-Smith \& Sterelny (2016) or Downes \& Matthews (2020).

Self-environment distinction is also important in our understanding of consciousness (Van Gulick, 2018). For example, our experience of qualia depends on introspection from what we presume to be a shared environment. Our intentionality towards objects other than ourselves rests likewise. From considerations such as these, provision of a principled basis for distinction between self and environment would be a comparably important function of the inner ear as its hearing function.

\subsection{Discussion}

This section describes a general application of the Concurrency Hypothesis to speech-motor research and auditory scene analysis. Section 3 will build on the discussion in this section to describe a specific application of the Concurrency Hypothesis to explanation of stuttering.

\subsubsection{Application to speech-motor research}

An own voice auditory stream would provide a target for the proposed efference copy of the speech plan in predictive feedback control models (e.g. Hickok \& Poeppel, 2007; Roelofs \& Meyer, 1999; Tourville \& Guenther, 2011). If applied to speech-motor models, the Concurrency Hypothesis has potential to improve explanatory power.

A corollary of this proposal is that if the Concurrency Hypothesis is to be tested, speech-motor research should use physiologically valid own voice stimuli. Physiologically valid own voice stimuli are those containing concurrent $\mathrm{AC}$ sound and $\mathrm{BC}$ vibration, with relative composition and timing as described in figure 1 and table 1. 
Creation of such stimuli carries practical difficulty. For example, an ideal test of speech-motor activity would compare brain activity during identical sound and vibrational stimuli in two conditions. The first condition is the standard articulatory process: brain activity generates sound and vibration following coordinated nerve impulses to articulatory muscles, whilst at the same time brain activity is altered following deflection of inner ear mechanoreceptors by the sound and vibration produced during articulation. The second condition should be identical to the first, but without the activity in articulatory muscles being created by brain activity. Instead, the measured brain activity would be solely in response to the sound and vibration produced by articulatory muscles. Unfortunately, the experimental arrangement in the second condition is difficult or impossible even in animal models. The articulatory muscles could in principle be made to produce sound and vibrational stimuli similar to that during vocalisation, for example through electrical stimulus to the articulatory muscles. However, the process of doing so would either be highly traumatic to the host animal, or the animal would have to be sedated. Whatever experimental arrangement is chosen, resting state brain activity in the second condition would differ from that of the first condition (the standard articulatory process) to the extent that comparison of brain activity between the two conditions would be overwhelmingly difficult to interpret.

Accordingly, much testing of brain activity during articulation, or vocalisation, has been based around a simpler comparison. The first condition is the standard articulatory process (i.e. as previously defined), with simultaneous recording of brain activity (e.g. by electrophysiology) and the sound and/or vibrations created during articulation (e.g. using a microphone). The second condition comprises a recording of brain activity without articulation, whilst the sound and/or vibration recorded in the first condition is played back. This comparison would seem to overcome the difficulty with having articulatory muscles create the sound and vibration in the second condition. However, there is a disanalogy in that the sound and vibration in the second condition are not identical to the sound and vibration in the first condition. This disanalogy has potential to invalidate the intended comparison.

Thus, protocols intended to compare brain activity during articulation and the playback of a recording of vocalisation must choose a methodology for recording and playback of the sound and/or vibration. Possibilities are shown in a Latin square in figure 5 . Of these, speech-motor investigation has overwhelmingly compared the own voice condition with $\mathrm{dAC}$ playback of a dAC recording. Often, participants are invited to adjust sound pressure levels of $d A C$ playback so as to perceptually match the loudness of the $A C / B C$ combination heard during vocalisation. Doing so does not create a stimulus comparable to the stimulus present during vocalisation. Own voice is perceived through an approximately equal combination of air- and body-conducted stimuli (von Békésy, 1949; Pörschmann, 2000; Reinfeldt et al., 2010). Perceptual doubling of the loudness of the AC stimulus, to compensate for the absence of $B C$ stimulus, will for most participants correspond to no more than a $10 \mathrm{~dB}$ increase in sound pressure level (Stevens, 1972; Warren, 1973; Florentine, Popper \& Fay, 2010). Such an increase will barely bring the $A C$ stimulus to vestibular threshold, which for $A C$ is $10 \mathrm{~dB}$ above the $60 \mathrm{dBA}$ level typical of conversational speech. The $A C$ vestibular threshold is moreover $35 \mathrm{~dB}$ above the $\mathrm{BC}$ vestibular threshold (McNerney \& Burkard, 2011; Welgampola, Rosengren, Halmagyi \& Colebatch, 2003). 


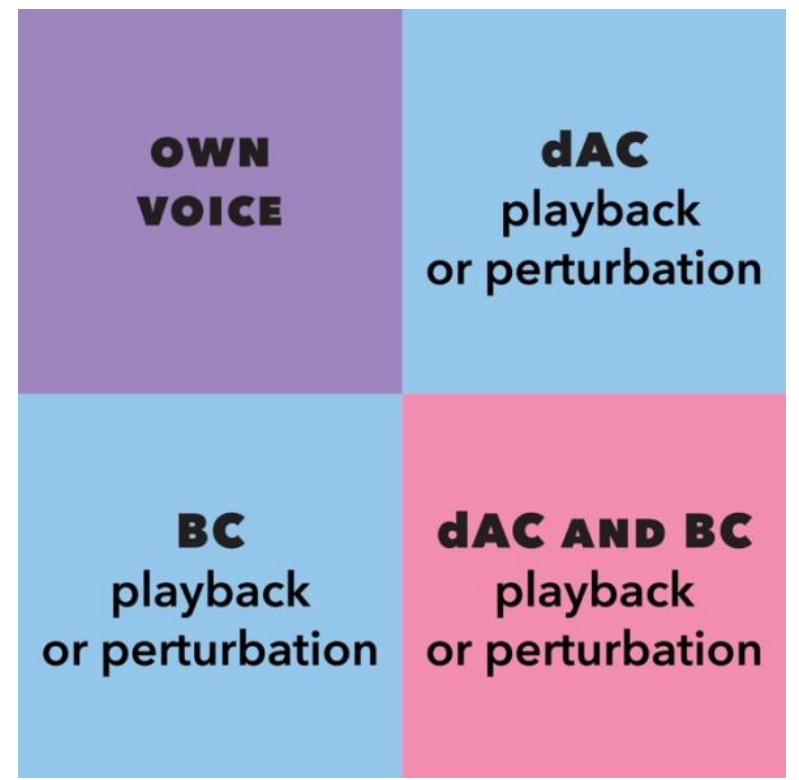

Figure 5: Latin square showing sound and vibrational stimuli which could be used in brain studies of own voice audition. The "own voice" condition is the standard articulatory process. It includes speechmotor brain activity which results in articulation generating $\mathrm{dAC}$ and $\mathrm{AAC}$ sound, and BC vibration; and at the same time includes the brain activity following deflection of inner ear mechanoreceptors by the $\mathrm{dAC}$ and rAC sound, and BC vibration, produced during articulation. "Playback" refers to playback of recordings of sound or vibration made during the standard articulatory process. Playback conditions do not contain speech-motor activity, unless digitally processed playback with a short delay (usually 10 ms or more) is presented concurrently with ongoing articulation. Such short latency digital manipulation is referred to as perturbation, and may also include manipulations to recordings (e.g. frequency shifts or changes to the nature of formants). A limitation for any type of playback is that the sound and vibrational stimuli present in the own voice condition cannot be recreated exactly using the earphones and bone vibrators available in laboratories. Combined air-and body-conducted (AC/BC) playback according to the timings provided in table 1 (i.e. AC and BC playback with binaural arrival at the inner ear coincident to $\sim 0.1 \mathrm{~ms}$ ) offers the closest approximation to the sound and vibrational stimuli present in the own voice condition. Not shown in the diagram is that BC stimulus can be subdivided into levels above and below vestibular threshold. BC stimulus should be above vestibular threshold, and $A C$ stimulus below vestibular threshold, to mimic stimuli present during articulation.

It follows that even after a sound pressure level increase to perceptually match the loudness of own voice, stimulation due to AC playback will either deflect vestibular mechanoreceptors very weakly in comparison to the $\mathrm{BC}$ stimulation present during vocalisation, or stimulation due to AC playback will not deflect vestibular mechanoreceptors at all. Firing rates of the vestibular ganglion will be altered barely or not at all from resting state. Action potentials along the VIII cranial nerve will predominantly be altered according to deflection of cochlear mechanoreceptors by AC playback, and an auditory stream corresponding to own voice will not be identified through coincidence detection between cochlear and vestibular streams as per the Concurrency Hypothesis.

Many functional imaging studies have compared vocalisation to AC playback of own voice recordings (e.g. with human participants: Numminen et al., 1998; Numminen \& Curio, 1999; Curio et al., 2000; Ford et al., 2001; Houde et al., 2002; Ford \& Mathalon, 2004; Ventura et al., 2009; Greenlee et al., 2011; Sato \& Shiller, 2018; or using animal models: Müller-Preuss \& Ploog, 1981; Eliades \& Wang, 2017; Eliades \& Tsunada, 2018). A consistent finding in such experiments is that parts of temporal cortex which respond 
to sound have reduced activity in the vocalisation condition compared to the playback condition. This has been interpreted as speech-motor activity modulating the temporal cortex (Hickok et al., 2011; Parrell \& Houde, 2019). The interpretation is consistent with theoretical models in which attenuating auditory feedback increases accuracy of state estimates of the speech-motor system (Parrell et al., 2019).

Whilst an attractive explanation, motor induced suppression of temporal cortex is not strongly supported by studies comparing vocalisation and AC playback conditions. The reason for this is that vocalisation and playback stimuli differ (as per figure 5), meaning that the observed reduction in temporal cortex activity cannot conclusively be attributed to speech-motor activity modulating temporal cortex. An alternative explanation is that the observed reduction in temporal cortex activity is due to the difference in stimuli between vocalisation and AC playback conditions. The Concurrency Hypothesis is consistent with this alternative explanation. The Concurrency Hypothesis adds the detail that in the vocalisation condition, firing rates of neurons in the ascending auditory pathway will uniquely identify own voice through coincidence detection of cochlear and vestibular afferents. Whereas in the AC playback condition, the ascending auditory pathway functions as it would with any ambient AC stimulus (i.e. as per Irvine 1992; Bregman, 1990).

It is possible that both explanations are correct: that an own voice auditory stream modifies temporal cortex activity, and that articulation modifies temporal cortex activity independently of audition. Exploring these possibilities offers the opportunity to increase explanatory power of speech-motor models, and to make testable predictions. In doing so it is not necessary to use the Concurrency Hypothesis. However, alternatives would be to propose a different method by which own voice is identified as an ascending auditory stream (i.e. a solution to the ill-posed problem of sound source discrimination in auditory scene analysis), or else to stipulate that an auditory target map for own speech is innately specified (e.g. as per Liberman \& Mattingly, 1985).

Studies using playback of own voice recordings could be reinterpreted in light of these considerations, and extended to include BC stimuli. Auditory perturbation studies could be similarly reinterpreted (e.g. McGuire et al., 1996; Hirano et al., 1997; Fu et al., 2006; Parkinson et al., 2012; Toyomura et al., 2007; Zarate \& Zatorre, 2008; Tourville et al., 2008; Zheng et al., 2009; Zarate et al., 2010). In auditory perturbation studies, vocalisation is recorded, is optionally digitally manipulated, and is played back with a short delay whilst articulation is ongoing. Examples of manipulation include frequency shift or alteration of formants. Recording and playback use AC sound. Digital processing (e.g. with fast Fourier transform) introduces delays which are typically $10 \mathrm{~ms}$ or more. Such delays are at least an order of magnitude larger than the sub-millisecond timings in table 1 . Thus, auditory perturbation studies assess the effect of keeping the $\mathrm{BC}$ vibrational stimulus of vocalisation unchanged, whilst adding a delayed $\mathrm{AC}$ stimulus having similar spectral characteristics to the ongoing vocalisation. Effectively they manipulate $r A C$ and (if using insert earphones) attenuate $d A C$. The protocol could be extended to form part of a larger range of investigation in which $\mathrm{BC}$, and combined $\mathrm{AC} / \mathrm{BC}$, manipulations are also evaluated.

The Latin square in figure 5 is a simplification. Stimuli can be further subdivided into those above and below vestibular threshold. Todd et al. (2014a, 2014b) compared cortical response to stimuli above and below vestibular threshold. Electroencephalography showed morphological change in and around the N1 wave upon crossing vestibular threshold, with source analysis indicating origin in cingulate or temporal cortex. The $\mathrm{N} 1$ wave (or its M100 equivalent in magnetoencephalography) is the component found to have reduced amplitude when brain activity during vocalisation is compared to brain activity during AC playback of vocalisation. Thus, the suggestion is that in studies comparing vocalisation and playback conditions, the observed brain activity will differ depending on whether playback stimuli are above or 
below vestibular threshold. A physiologically valid own voice stimulus will combine $B C$ stimulus above vestibular threshold with $A C$ stimulus below vestibular threshold. Follow-up work to the current article will appraise brain activity following combinations of $B C$ and $A C$ stimuli which are respectively above and below vestibular threshold.

\subsubsection{Application to Auditory Scene Analysis}

Bregman (1990) proposed that auditory scenes are generated from the neural firing patterns elicited when sound waves are coincident on the biomechanical structure of the middle and inner ears. Auditory scenes would contain detail consistent with our perceptual experience. Two processes are proposed to identify the auditory streams which comprise auditory scenes. Firstly, primitives, which are general purpose segregation and grouping processes based on those developed by the Gestalt school (e.g. common onset, harmonicity, spectral composition, co-variation in amplitude; Carlyon, 2004; Darwin, 2007; Ciocca, 2008; Denham \& Winkler, 2015; Młynarski \& McDermott, 2019). Secondly, schemas, which are specific processes identifying certain types of sound (e.g. conspecific animal vocalisations or phonemes in human speech; Bey \& McAdams, 2002; Billig et al., 2013; Woods \& McDermott, 2018).

The Concurrency Hypothesis could be the basis of a schema identifying own voice. Modelling of auditory scene analysis is an active research area (Cooke \& Ellis, 2001; Haykin \& Chen, 2005; Snyder \& Alain, 2007; Winkler et al., 2009; Szabó, Denham \& Winkler. 2016; Snyder \& Elhilali, 2017; Chakrabarty \& Elhilali, 2019). Whichever modelling approach is taken, the Concurrency Hypothesis would be applied through the following principles:

i. Primitive processes are proposed to act on neural firing patterns elicited by deflection of vestibular mechanoreceptors as well as by deflection of cochlear mechanoreceptors.

ii. Whenever firing patterns of vestibular and cochlear origin have similar attributes as identified by primitives, the firing patterns are likely to correspond to own voice.

iii. Activity in the auditory brainstem (BinKhamis et al., 2019) is consistent with substantial processing of speech sounds. As such, models will have greater neurological plausibility if the coincidence detection in (ii) occurs very early in the ascending auditory pathway - for example, in the cochlear nucleus or the superior olivary complex.

iv. Computational modelling of coincidence detection (e.g. through vestibular input to octopus cells in the cochlear nucleus) may require primitives and schemas to be entwined.

An own voice identification schema based on ( $\mathrm{i}-\mathrm{iv})$ could underpin further schemas. Possibilities are:

v. Vocalisation of conspecifics is likely to be occurring when primitives identify similar neural firing patterns (e.g. spectral composition typical of formants) to those present during own voice coincidence detection, but when vocalisation is not being produced and neural firing patterns arise from cochlear mechanoreceptors only.

vi. If stored in short-term memory, an own voice auditory stream could be compared via primitives to the $\mathrm{rAC}$ reflections of own voice (see figure 2 and table 1 ) to create a schema identifying reflection and reverberation.

vii. Multisensory integration (Stein \& Stanford, 2008) of reflections and reverberations from (vi) with head and body position could support a schema for echolocation (see review of human echolocation in Kolarik et al., 2014).

viii. Sound source learning based on (vii), in combination with the generalised vocalisation schema of (v), could support a schema distinguishing sources in multi-speaker scenarios. 
ix. Adaptation of the schema in (viii) for sounds other than vocalisation could reinforce learning of sound source location using primitives.

These ideas need development into computational models. The underlying point is that many or all of the schemas required by auditory scene analysis could be based on the Concurrency Hypothesis. The high energy vocalisations of neonates (e.g. crying or wailing) have more than sufficient energy to deflect both cochlear and vestibular mechanoreceptors, meaning that auditory learning based on the Concurrency Hypothesis would begin at birth (and quite possibly, would have a precursor based on the mother's voice in utero).

\section{Hypotheses of Stuttering}

\subsection{Explanatory targets}

Explanatory targets for stuttering are extensive. Table 2 shows process explananda (how stuttering happens), whilst table 3 shows contrastive explananda (why stuttering happens). These lists are not intended as exhaustive, but are rather presented as minimal criteria which any hypothesis of stuttering should address.

Priority will be given to addressing process explananda. This is not to downplay the importance of contrastive explananda for stuttering research. However, a comprehensive discussion of contrastive explananda for stuttering (e.g. why there is a sex difference; the role of heredity; whether a particular brain study reflects causation, consequences or correlates of stuttering) encompasses issues wider than those within stuttering research, and is accordingly outside the scope of this article. The current aim is of adequacy for process explanans, with contrastive explanans added as part of ongoing research.

\begin{tabular}{|c|c|c|}
\hline Explananda & Examples & References \\
\hline $\begin{array}{l}\text { Core stuttering } \\
\text { behaviours }\end{array}$ & $\begin{array}{l}\text { Prolongation or repetition of speech sounds, including } \\
\text { silent blocks to airflow. }\end{array}$ & $\begin{array}{l}\text { Van Riper }(1982, \text { ch } 6) ; \\
\text { Bloodstein }(1995, \text { ch } 1-2) \\
\text { Ward }(2006, \text { ch } 1,7,9)\end{array}$ \\
\hline $\begin{array}{l}\text { Accessory and } \\
\text { interiorised } \\
\text { stuttering } \\
\text { behaviours }\end{array}$ & $\begin{array}{l}\text { Accessory stuttering includes excess tension or } \\
\text { tremor in articulatory muscles; perseveration; } \\
\text { changes in breathing; use of fixed posture; } \\
\text { postponement of words or substitution of synonyms; } \\
\text { and movement of non-articulatory muscles, including } \\
\text { limb movements, especially in attempts to time or } \\
\text { disguise movement of articulatory muscles. } \\
\text { Interiorised stuttering adds word, phoneme or } \\
\text { situation fears; situation avoidance; frustration, } \\
\text { hostility and guilt. See Iverach et al. (2017) for } \\
\text { discussion of overlap between stuttering and social } \\
\text { anxiety. }\end{array}$ & $\begin{array}{l}\text { Van Riper (1982 ch 6, 7, 11); } \\
\text { Bloodstein }(1995, \text { ch } 1-2) ; \\
\text { Ward (2006, ch } 1,7,9) \\
\text { Iverach et al. (2017) }\end{array}$ \\
\hline $\begin{array}{l}\text { Linguistic and/or } \\
\text { situational }\end{array}$ & $\begin{array}{l}\text { Stuttering increases with propositionality of content. } \\
\text { Stuttering is reduced when speaking alone or to } \\
\text { animals. Stuttering increases when talking to } \\
\text { authority figures, or when the audience appears } \\
\text { distracted. Stuttering is mostly word initial, and } \\
\text { almost never on the last sound of a word or syntactic } \\
\text { structure. Stuttering tends to occur at the beginning } \\
\text { of a sentence or grammatical clause. Accented } \\
\text { syllables are more likely to be stuttered. Adults tend }\end{array}$ & $\begin{array}{l}\text { Richels et al. (2010); } \\
\text { Buhr \& Zebrowski (2009); } \\
\text { Bloodstein }(2002,2006) ; \\
\text { Ward (2006, ch 5); } \\
\text { Karniol (1995); } \\
\text { Bloodstein }(1995, \text { ch 7); } \\
\text { Van Riper (1982 ch 8); } \\
\text { Langová \& Sváb (1973); } \\
\text { Sheehan et al. (1967); }\end{array}$ \\
\hline
\end{tabular}




\begin{tabular}{|c|c|c|}
\hline & $\begin{array}{l}\text { to stutter on longer words, on words starting with } \\
\text { consonants, and on words with low transition } \\
\text { probability (high information load). Adults tend to } \\
\text { stutter on content rather than function words, and } \\
\text { vice versa for children. }\end{array}$ & $\begin{array}{l}\text { Gould \& Sheehan (1967); } \\
\text { Eisenson \& Horowitz (1945) }\end{array}$ \\
\hline $\begin{array}{l}\text { Anticipation, } \\
\text { Consistency and } \\
\text { Adjacency }\end{array}$ & $\begin{array}{l}\text { People who stutter can predict when stuttering will } \\
\text { occur with high accuracy. In successive oral readings } \\
\text { of the same material, stuttering tends to occur on the } \\
\text { same syllables. If previously stuttered words are } \\
\text { blotted out, stuttering on subsequent readings tends } \\
\text { to be on words adjacent to those previously } \\
\text { stuttered. }\end{array}$ & $\begin{array}{l}\text { Garcia-Barrera \& Davidow (2015); } \\
\text { Brocklehurst et al. (2013); } \\
\text { Jackson et al. (2015); } \\
\text { Bloodstein (1995, ch 7); }\end{array}$ \\
\hline Adaptation & $\begin{array}{l}\text { Stuttering is reduced in successive oral readings of the } \\
\text { same material (occurs simultaneously with the } \\
\text { consistency effect). }\end{array}$ & $\begin{array}{l}\text { Brocklehurst et al. (2013); } \\
\text { Max \& Baldwin }(2010) \\
\text { Bloodstein }(1995, \text { ch 8); } \\
\text { Wingate }(1986 a, b)\end{array}$ \\
\hline $\begin{array}{l}\text { Operant } \\
\text { conditioning }\end{array}$ & $\begin{array}{l}\text { Stuttering is reduced in response-contingent } \\
\text { stimulation experiments (e.g. when using electric } \\
\text { shock or time out during stuttered moments). }\end{array}$ & $\begin{array}{l}\text { Ingham }(1984, \text { ch 9); } \\
\text { Nittrouer \& Cheney (1984); } \\
\text { Bloodstein }(1995, \text { ch 8) }\end{array}$ \\
\hline $\begin{array}{l}\text { Alteration to } \\
\text { audition during } \\
\text { speech }\end{array}$ & $\begin{array}{l}\text { Many changes to audition during speech can reduce } \\
\text { stuttering. Effective changes include delay; frequency } \\
\text { shift; masking; and unison speaking with, or } \\
\text { shadowing of, a second speaker. }\end{array}$ & $\begin{array}{l}\text { Bloodstein }(1995, \text { ch } 2,8) ; \\
\text { Van Riper (1982 ch 15); } \\
\text { Ingham }(1984, \text { ch } 10) ; \\
\text { Ward (2006, ch 3); } \\
\text { Howell et al. (1987); } \\
\text { Yates (1963) }\end{array}$ \\
\hline $\begin{array}{l}\text { Alteration to } \\
\text { stress patterns } \\
\text { within } \\
\text { vocalisation }\end{array}$ & $\begin{array}{l}\text { Speaking in time with a metronome reduces } \\
\text { stuttering, as does singing. }\end{array}$ & $\begin{array}{l}\text { Van Riper }(1982 \text { ch } 15,17) \\
\text { Bloodstein }(1995, \text { ch } 2,8) \\
\text { Wingate }(1969)\end{array}$ \\
\hline $\begin{array}{l}\text { Therapy } \\
\text { effectiveness }\end{array}$ & $\begin{array}{l}\text { Interventions for stuttering have an overall positive } \\
\text { effect, although some stuttering usually remains post- } \\
\text { intervention. Methodical comparison of interventions } \\
\text { is difficult. No intervention is clearly preferred. }\end{array}$ & $\begin{array}{l}\text { Johnson et al. (2015); } \\
\text { Baxter et al. (2015); } \\
\text { Herder et al. (2006); } \\
\text { Ward (2006 ch 15) }\end{array}$ \\
\hline
\end{tabular}

Table 2: Process explananda for stuttering

\begin{tabular}{|c|c|c|}
\hline Explananda & Examples & References \\
\hline Age of onset & $\begin{array}{l}\text { Childhood stuttering has a median age of onset } \\
\text { between 3-4 years, with a positively skewed } \\
\text { distribution and upper limit around 9-12 years. } \\
\text { Childhood cases are mostly developmental, but some } \\
\text { may be acquired (neurogenic or psychogenic). See } \\
\text { Ward (2006, ch 7), Yairi (2007) or Seery et al. (2007) } \\
\text { for review of subtypes in children and Van Borsel } \\
\text { (2014) for review of acquired stuttering. Adult onset } \\
\text { is rare. Adult onset may be acquired, and/or re- } \\
\text { emergent childhood stuttering (Van Riper, 1982, } \\
\text { p64). }\end{array}$ & $\begin{array}{l}\text { Yairi \& Ambrose (2013); } \\
\text { Bloodstein (1995 ch 3,6); } \\
\text { Craig et al. (2002); } \\
\text { Månsson (2000); } \\
\text { Andrews \& Harris (1964) }\end{array}$ \\
\hline Heredity & $\begin{array}{l}\text { Averaging across seven twin studies gives a } \\
\text { heritability estimate for PDS at 70\% ( } 95 \% \mathrm{Cl} 59-81 \% \text {, } \\
\text { studies compiled in Frigerio-Domingues \& Drayna, } \\
\text { 2017). Prospective genetic variations for stuttering } \\
\text { have been identified through linkage analysis. Knock- }\end{array}$ & $\begin{array}{l}\text { Benito-Aragón et al. (2020) } \\
\text { Frigerio-Domingues \& Drayna } \\
\text { (2017); } \\
\text { Kraft \& Yairi (2012); } \\
\text { Ward (2006, ch 7); }\end{array}$ \\
\hline
\end{tabular}




\begin{tabular}{|c|c|c|}
\hline & $\begin{array}{l}\text { in mice carrying one of these variations show } \\
\text { stuttering in their ultrasonic vocalisations (Han et al. } \\
\text { 2019). }\end{array}$ & Bloodstein $(1995, \mathrm{ch} 3)$ \\
\hline $\begin{array}{l}\text { Incidence and } \\
\text { prevalence }\end{array}$ & $\begin{array}{l}\text { Incidence (fraction of the population who have ever } \\
\text { stuttered) is between 5-8\%. Lifespan prevalence } \\
\text { (fraction of the entire population who stutter) is } \\
0.72 \% \text {, but prevalence can be much higher (e.g. } 2- \\
4 \% \text { ) with cohorts aged younger than } 12 \text { years, and } \\
\text { especially those between } 2-6 \text { years. }\end{array}$ & $\begin{array}{l}\text { Yairi \& Ambrose (2013); } \\
\text { Bloodstein (1995 ch 3,6); } \\
\text { Craig et al. (2002); } \\
\text { Månsson (2000); } \\
\text { Andrews \& Harris (1964) }\end{array}$ \\
\hline Sex differences & $\begin{array}{l}\text { At the typical onset age of } 3-4 \text { years old, about } 1.5 \\
\text { times more boys than girls stutter. By adulthood, } 3 \text { or } \\
4 \text { times more men than women will stutter. Thus, } \\
\text { boys are more likely than girls to start stuttering. And } \\
\text { girls are more likely than boys to stop stuttering. } \\
\text { Drayna et al. (1999) find PWS are more likely to be } \\
\text { male in cases with no family history of stuttering (see } \\
\text { also Ambrose et al., 1997). }\end{array}$ & $\begin{array}{l}\text { Yairi \& Ambrose (2013); } \\
\text { Bloodstein (1995 ch 3,6); } \\
\text { Craig et al. (2002); } \\
\text { Månsson (2000); } \\
\text { Andrews \& Harris (1964) }\end{array}$ \\
\hline $\begin{array}{l}\text { Childhood stuttering } \\
\text { is frequently } \\
\text { transient }\end{array}$ & $\begin{array}{l}\text { Incidence and prevalence data show many children } \\
\text { who stutter (60-80\%) will stop stuttering, with or } \\
\text { without intervention. Systematic review of } 35 \text { studies } \\
\text { (Sugathan et al., 2020) indicates speech features as } \\
\text { predictive of stuttering continuing into adulthood } \\
\text { (more stuttering-like dysfluencies including } \\
\text { dysrhythmic phonation and monosyllabic word } \\
\text { repetition; higher articulatory rate; lower score in } \\
\text { phonology tests). Meta-analysis of } 11 \text { studies (Singer } \\
\text { et al., 2020) adds predictors of: male sex; greater age } \\
\text { at onset; heredity; and lower scores in tests of } \\
\text { language skills. }\end{array}$ & $\begin{array}{l}\text { Yairi \& Ambrose (2013); } \\
\text { Sugathan et al. (2020); } \\
\text { Singer et al. (2020) }\end{array}$ \\
\hline $\begin{array}{l}\text { Co-occurring } \\
\text { diagnoses }\end{array}$ & $\begin{array}{l}\text { Blood et al. (2003), in a survey of } 1184 \text { speech and } \\
\text { language pathologists (SLPs), found } 37 \% \text { of } 2628 \\
\text { children who stuttered had no co-occurring } \\
\text { diagnosable condition. The remaining } 63 \% \text { had an } \\
\text { average of } 2.2 \text { co-occurring diagnosable conditions. } \\
\text { Of these, } 33.5 \% \text { were articulatory, } 25.6 \% \text { concerned } \\
\text { expressive or receptive semantics, and } 34.5 \% \text { were } \\
\text { non-speech-language (including learning, literacy, } \\
\text { attention deficit and central auditory processing). An } \\
\text { earlier survey of SLPs (Arndt \& Healey, 2001) found } \\
44 \% \text { of } 467 \text { children who stuttered had a co- } \\
\text { occurring phonological and/or language diagnosis. } \\
\text { There is overlap between stuttering and dyslexia } \\
\text { (Elsherif et al., } 2021 \text { ). Generalised household surveys } \\
\text { also show a high co-occurrence for stuttering with } \\
\text { other developmental categories in self or parent } \\
\text { report. Retrospective self-report from adults with } \\
\text { latent class analysis (Ajdacic-Gross et al., } 2018 ; \text { see } \\
\text { also } 2010 \text { ), established association with atopic } \\
\text { disease (e.g. allergy or asthma); psychosocial } \\
\text { adversity in childhood; or neurodevelopmental or } \\
\text { early anxiety disorder. However, such co-occurences } \\
\text { were only present in one of two subgroups. }\end{array}$ & $\begin{array}{l}\text { Elsherif et al. (2021); } \\
\text { Briley \& Ellis (2018); } \\
\text { Ajdacic-Gross et al. (2018); } \\
\text { Ajdacic-Gross et al. (2010); } \\
\text { Boulet et al. (2009); } \\
\text { Blood et al. (2003); } \\
\text { Arndt \& Healey (2001); } \\
\text { Bloodstein (1995, ch 4-6) }\end{array}$ \\
\hline $\begin{array}{l}\text { Subtle differences } \\
\text { from controls }\end{array}$ & $\begin{array}{l}\text { Subtle differences can be found between adults or } \\
\text { children who do and do not stutter for tasks } \\
\text { involving general motor control. Sometimes } \\
\text { differences in the integration of motor control with } \\
\text { timing systems, and/or sensory or proprioceptive } \\
\text { input, are implied. Examples include movement } \\
\text { initiation latency and movement duration, and }\end{array}$ & $\begin{array}{l}\text { Choo et al. (2020); } \\
\text { Ofoe et al. (2018); } \\
\text { Ntourou et al. (2011); } \\
\text { Max (2004); } \\
\text { Bloodstein (1995); } \\
\text { Rosenfield \& Jerger (1984) }\end{array}$ \\
\hline
\end{tabular}




\begin{tabular}{|c|c|c|}
\hline & $\begin{array}{l}\text { involve use of effectors such as fingers and hands as } \\
\text { well as use of the orofacial system (Max, 2004). } \\
\text { Subtle differences are also found in many tests of } \\
\text { central auditory function (review in Rosenfield \& } \\
\text { Jerger, 1984). Meta-analysis of language tests in } \\
\text { children who stutter (receptive and expressive } \\
\text { vocabulary, mean length of utterance, syntactic } \\
\text { complexity, homogeneity analysis) shows subtle } \\
\text { rather than clinically significant differences from } \\
\text { controls (Ntourou et al., 2010). Similarly subtle } \\
\text { differences between children who do and do not } \\
\text { stutter are reported in tests related to attention and } \\
\text { executive function (Ofoe et al., 2018; Choo et al., } \\
\text { 2020). }\end{array}$ & \\
\hline Neurotransmitters & $\begin{array}{l}\text { Positron Electron Tomography and drug trials } \\
\text { indicate that neurotransmitters influence stuttering } \\
\text { behaviour. Dopamine levels appear particularly } \\
\text { important. }\end{array}$ & $\begin{array}{l}\text { Maguire et al. (2020); } \\
\text { Metzger et al. (2017); } \\
\text { Wu et al. (1997) }\end{array}$ \\
\hline Neuroimaging & $\begin{array}{l}\text { Differences from controls in areas important for } \\
\text { auditory, language and speech-motor function. See } \\
\text { discussion in section 3.4.1. }\end{array}$ & $\begin{array}{l}\text { Etchell et al. (2017); Neef et al. } \\
\text { (2015); Belyk et al. (2015); } \\
\text { Budde et al. (2014) }\end{array}$ \\
\hline
\end{tabular}

Table 3: Contrastive explananda for stuttering

\subsection{Candidate explanations}

Bloodstein (1995) categorises hypotheses of the moment of stuttering into three groups: repressed needs, anticipatory struggle, and breakdown. Research and theoretical development over the last 30 years has overwhelmingly focussed on breakdown hypotheses. As such, repressed needs hypotheses and anticipatory struggle hypotheses will be reviewed only in brief, whilst breakdown hypotheses will be described in greater detail.

\subsubsection{Repressed Needs Hypotheses}

Originating in the psychoanalytic schools of the 1920s and 1930s, repressed needs hypotheses describe stuttering as a neurotic symptom rooted in unconscious needs. Such hypotheses are outside the mainstream of contemporary stuttering research (Martin, 2016).

\subsubsection{Anticipatory Struggle Hypotheses}

518 In anticipatory struggle hypotheses, stuttering is preceded by the speaker's prediction that speech will be 519 difficult to execute. The prediction of difficulty leads to increased muscular tension. The increased muscular tension in turn impairs the coordination usually present during speech, and causes the speech attempt to be stuttered.

Anticipatory struggle hypotheses have seen little development in the last 50 years. For a historical survey, see Bloodstein (1995, ch 2), and for a contemporary perspective see Brocklehurst et al. (2013).

\subsubsection{Breakdown Hypotheses}

525 In breakdown hypotheses, stuttering is a behavioural manifestation of vulnerability in speaking ability.

526 The vulnerability is generally proposed to occur in either the language encoding or the speech-motor 
system. Breakdown of the vulnerable system is typically attributed to emotional or psychosocial stress (Bloodstein, 1995, p60).

\subsubsection{Language encoding breakdown}

Language encoding breakdown has been described in what Levelt $(1989,1999)$ refers to as the Formulator. This is a hypothesised stage of speech production between thought and expression, in which lexical and syntactic selection, along with morphological, phonological and phonetic encoding, precedes creation of a motor plan. Levelt's model is shown in figure 6. The Formulator can be described using a spreading activation network (e.g. Dell, 1986; Dell \& O'Seaghdha, 1991). In network models, a metrical frame is created for a planned utterance. Phonological segment nodes will then compete for selection, with the nodes filling the frame being those which have the highest activation level at the moment when speech-motor planning commences.

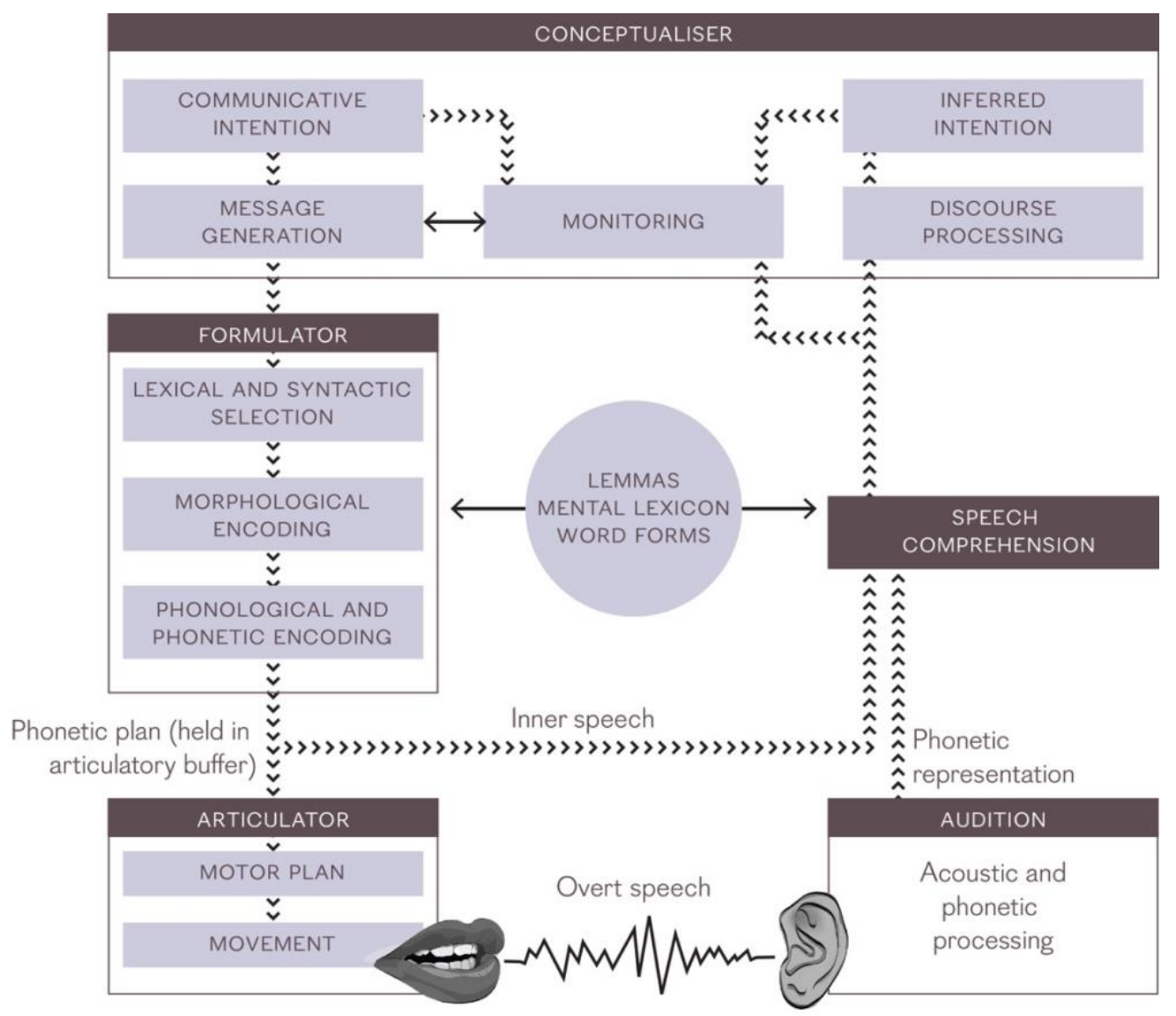

Figure 6: Speech production model of Levelt (1989; see also Levelt et al., 1999). Notable features are an inner and an outer loop, with the parsimony of a shared mental lexicon. Stages include Audition, Speech Comprehension, Conceptualisation, Formulation and Articulation. The Concurrency Hypothesis concerns activity in Audition, and thus addresses a special case of auditory scene analysis (Bregman, 1990). Discussion of Speech Comprehension can be found in Norris et al. (2000), Galantucci et al. (2006) or Poeppel et al. (2008), among others. There is no widely agreed model of the Conceptualiser; any effort to produce one touches on long-standing issues in Cognitive Science, Philosophy of Psychology and Philosophy of Mind (several other hypotheses of the Levelt model, and hypotheses of its constituents, do likewise). Indefrey \& Levelt (2004) present a meta-analysis, based on neuroimaging literature, of the time course for processes within the Formulator; see also section 3.2.3.1 for discussion of Dell's (1986) spreading activation network model of the Formulator. Articulation is 2019). 
(C) Creative Commons 4.0 licence. Based on Levelt (1989), Levelt et al. (1999), Indefrey \& Levelt (2004).

The Covert Repair Hypothesis (Postma \& Kolk, 1993) postulates slower than usual activity in the selection. If inappropriate nodes are selected, two possibilities pertain. If the inappropriate nodes are detected prior to articulation (e.g. via an internal monitoring loop), they are repaired covertly. This repair manifests as a silent pause - the speaker wishes to continue, but cannot do so at that moment. Alternatively, if inappropriate nodes are detected during articulation, the speaker will stop and retrace. Phonemes uttered prior to retrace are audible as stuttering for however many reformulations are necessary to correct the speech plan. A variant on this theme is offered by the Vicious Circle Hypothesis (Vasić \& Wijnen, 2005; Bernstein Ratner \& Wijnen, 2007), which proposes that it is over-vigilance in repair, rather than slower than usual formulation, which causes stuttering.

An alternative breakdown mechanism is described by Howell $(2004,2008)$. In the EXPLAN hypothesis, breakdown occurs when the rate of speech planning has fallen below that of execution. The available speech plan is repeatedly executed until a continuation of the speech plan is available. EXPLAN entails aspects of both psycholinguistic and speech-motor breakdown. The Variable Release Threshold hypothesis (Brocklehurst et al., 2013) modifies EXPLAN such that the release threshold for a phoneme will vary according to a modified version of Bloodstein's (1975) account of anticipatory struggle.

571

572

573

574

575

576

577

578

579

580

581

582

583

\subsubsection{Speech-motor breakdown}

Speech-motor breakdown is typically investigated through comparison of people who stutter in fluent versus stuttered speech (state comparison) or people who do and do not stutter during fluent speech (trait comparison). Outcome measurement is via neuroimaging, electromyography of articulatory muscles, or a hybrid design (e.g. studies employing transcranial magnetic stimulation). Differences are reliably and repeatedly established in both trait and state comparisons, and are present even below the threshold for behavioural observation of stuttered speech (Etchell et al., 2017; Neef et al., 2015; Belyk et al., 2015; Budde et al., 2014). Brain areas frequently identified include premotor cortex and the temporoparietal junction (including white matter connecting those areas), the cerebellum, and the basal ganglia. Stuttering can be emulated neurocomputationally by modelling the brain activity observed in neuroimaging of stuttering (Civier et al., 2013), with over-reliance on auditory feedback a contributing factor (Max et al., 2004; Civier et al., 2010). Arenas (2017) proposes an extension to speech-motor breakdown in which fluctuations in the vigilance of the monitoring system account for the contextual variability of stuttering.

\subsection{A Novel Account of Stuttering: REMATCH (Reflexivity and Communicative Mismatch)}

\subsubsection{Introduction}

This section introduces a novel account of stuttering with two core hypotheses: Reflexivity, and Communicative Mismatch. The combination is referred to as REMATCH. 
The first core hypothesis in REMATCH concerns a quale referred to as "reflexivity". It proposes that PWS have a subjective experience during speaking in which their own speech has increased salience in comparison to the way that people who do not stutter experience their own speech while speaking. The second describes communicative mismatch, in which a breakdown in communicative choreography between speaker and listener engenders observable stuttering behaviour. The reflexivity proposal develops the Concurrency Hypothesis described in section 2. It is a distal cause of stuttering relative to communicative mismatch.

This section will proceed as follows. The sequence of events leading to a moment of stuttering, consistent with the two core hypotheses, will be described. The core hypotheses will then be applied to the explananda in tables 2 and 3.

\subsubsection{Increased Reflexivity}

Consider that the subjective experience of seeing the colour red may differ between individuals, even if those individuals can mutually agree that the referenced colour is red (Tye, 2018). Similarly, different speakers may have differing subjective experiences of hearing their own voice during vocalisation. The proposal is that the subjective experience of hearing own voice during vocalisation differs in a principled and consistent manner between people who do and do not stutter.

This subjective experience, or quale, of own voice during vocalisation will henceforth be referred to as "reflexivity". It is related to self-awareness (Gallagher \& Zahavi, 2021; Smith, 2020). The exact proposal is that reflexivity is increased for PWS relative to controls. What is meant by increased reflexivity is that the phenomenal experience of own voice is more intense for PWS than for ordinarily fluent speakers. It is as if PWS were speaking through a magical megaphone, which broadcasts only inside the body, and whose effect is to increase salience of the message being delivered rather than volume of the utterance.

Empirical investigation of qualia is achievable through psychophysics, albeit with well-identified difficulties (Fodor, 1987). The proposal of reflexivity as a quale builds on the Concurrency Hypothesis described in section 2, and in particular it follows from the issues around evolution, cognitive science and philosophy of mind discussed in section 2.3.2.1. The hypothesis of Communicative Mismatch, to be introduced in section 3.3.1.2, proposes that a difference in subjective experience of the reflexivity quale between people who do and do not stutter is causative of stuttering behaviour.

A difference in reflexivity between people who do and do not stutter could be expected to coincide with a difference in the auditory feedback whose presence is integral to many types of psycholinguistic and speech-motor models. Alterations to auditory feedback are well-established as reducing stuttering for PWS (Yates, 1963; Howell et al., 1987; Kalinowski et al., 1993; Stuart et al., 2004; Foundas et al., 2013), and hyperfunctional monitoring in stuttering has been proposed from psycholinguistic (Bernstein Ratner, 1997; Bernstein Ratner \& Wijnen, 2007) and speech-motor (Arenas, 2017) perspectives. REMATCH is independent of any particular speech-motor or psycholinguistic model. For example, speech may be entirely under feed forward control, or else speech may be best described by paradigms which do away with mental representation entirely (e.g. certain types of dynamical system, or those of extended cognition). For readers who prefer to think in terms of feedback control, the idea would be that an entire person (including the history, personality, hopes, dreams, and so forth) is included in the feedback loop for own voice audition. See Mysak $(1969, \mathrm{ch} 7)$ for a systems control account of stuttering along these lines. 


\subsubsection{Communicative Mismatch}

When PWS describe moments of stuttering, the role of the audience and situation are among themes identified (Tichenor \& Yaruss, 2018). In a review of linguistic factors, Karniol (1995) suggests that the involvement of motor process in stuttering is a symptom rather than a cause. Pierre (2015), extending beyond linguistics to discuss societal convention more broadly, describes stuttered speech as marginalised relative to dominant choreographies of bodily and inter-bodily communicative practices.

To address perspectives such as these, stuttering will be considered not just as an interruption of speech, but moreover as an interruption of a speech act (i.e. speech act as per Austin, 1955). It will be based around the approach-avoidance conflict hypothesis of stuttering developed by Sheehan $(1953,1958$, $1970,1975)$. Approach-avoidance conflict was originally formulated as a Gestalt field theory by Lewin (1935). Conflict would follow incompatible goals - for example, accept a substantial pay rise (approach gradient), but only with unpaid weekend work at the employer's discretion (avoidance gradient). Sheehan (1958) proposed that stuttering is a double approach-avoidance conflict, in which "[The person who stutters] can speak, thus achieving his aim of communication, but at the cost of the shame and guilt he has learned to attach to his stuttering. Or he can remain silent, abandon communication, and suffer the frustration and guilt that such a retreat carries with it."

Sheehan was inspired by the work of Miller (1944) who trained rats in a runway first with a food goal, then with electric shock. When Miller presented the previously trained rats with a combination of a food goal and electric shock, the rats would display motor control vacillations similar to those observed in stuttering. In an earlier proposal along similar lines, Wyneken (1868; translated in Van Riper, 1982 p281) describes the will to speak during stuttering as "partially paralysed by doubt ... and one which is directly opposed to the will proper". Wyneken goes on to liken stuttering to "...when somebody, for example, wants to venture a jump, but in the very moment in which he leaps doubts that he will succeed. Often he can no longer stop the leap, but also does not jump with sufficient assurance, and so does not reach his goal."

The approach-avoidance proposal is updated in several ways. Firstly, the core hypothesis of increased reflexivity for PWS corresponds to own speech having increased salience when interpreted through the auditory system. Secondly, it is proposed that the unconscious interpretation of own speech operates with the high degree of automaticity proposed for unconscious processes in dual process theory (e.g. as per Evans, 2007; Kahneman, 2011). The double approach-avoidance conflict proposed by Sheehan is thus fragmented between unconscious and conscious processes. The final proposal is that stuttering occurs at times when there is uncertainty about the message being delivered. The uncertainty might, for example, relate to message content (e.g. whether the message being conveyed is accurate) or to message appropriateness (e.g. whether the message should be delivered to a particular audience, or at a particular time). The uncertainty could also be learned (e.g. from previous experience with stuttering this would account for the difficulty many who stutter have in saying their own name).

Putting all of these components together, the overall proposal is that whenever the speaker unconsciously interprets own speech with uncertainty, nerve signals are created which block the ongoing speech act. At the same time, the speaker notices difficulty and consciously generates nerve signals intended to continue the speech act. Articulatory muscles respond to both conscious and unconscious processes, and so simultaneously receive innervation which is consistent with completion and cessation of an utterance. The resultant activity is behaviourally observable as stuttering. Figure 7 summarises the activity diagrammatically. 


\section{STUTTERING DUE TO COMMUNICATIVE MISMATCH}

(1) The speaker interprets own speech with increased salience relative to speakers who do not stutter.

(2) When there is uncertainty over the message being articulated, unconscious processes create nerve signals blocking the ongoing speech act. At the same time. the speaker notices articulation difficulty, and redoubles conscious efforts to continue speaking*.

3 "Go" and "No go" nerve signals are simultaneously present in brain areas controlling speech-motor function.

(4) Observable stuttering behaviour results.

5 The process repeats, but audible stuttering changes the timing of unconscious own voice interpretation, and hence the timing of nerve signals blocking the ongoing speech act. Eventually the conscious process will win out, or the speaker will decide to do something else.

* The same process would underlie the occasional dysfluencies (e.g. fillers or word search) of ordinarily fluent speakers.

Figure 7: Stuttering due to communicative mismatch. This is based on the approach-avoidance conflict model of stuttering developed by Sheehan $(1953,1958,1970,1975)$, but updated to reflect contemporary understanding of unconscious processes.

\section{(C) Creative Commons 4.0 licence.}

From a psycholinguistic perspective, REMATCH places stuttering at the semantic-pragmatic interface. In Levelt's model (figure 6) stuttering would occur within the Conceptualiser. This differs from the psycholinguistic models in section 3.2.3.1, which place stuttering in the Formulator (or, for EXPLAN, between the the Formulator and Articulator). Section 3.4.1.2 will discuss a way to reconcile such psycholinguistic models within REMATCH.

\subsection{Explanatory Power}

\subsubsection{Biological considerations}

\subsubsection{Neurological substrate}

Systematic review of grey matter structural neuroimaging in adults who stutter (AWS) shows increased volume in the right superior temporal cortex and right precentral cortex compared to control groups of ordinarily fluent speakers (Etchell et al., 2017; see review for finer granularity and additional areas). These are homologues of areas in the left hemisphere thought to be important for speech and language (Hickok \& Poeppel, 2007). Activation likelihood estimation (ALE) meta-analysis of diffusor tensor imaging shows AWS have reduced fractional anisotropy in the callosal body, and in dorsal white matter tracts connecting grey matter regions considered important for auditory and motor function (Neef et al., 2015; see review for finer granularity and additional areas). Possible interpretations of reduced FA include demyelination, larger axon diameter, lower packing density or increased axonal membrane permeability 
(Jones et al., 2013). Fractional anisotropy does not detail direction of information flow between grey matter areas.

702

703

704

705

706

707

708

709

710

711

712

713

714

715

716

717

718

719

720

721

722

723

724

725

726

727

728

729

730

731

732

733

734

735

736

737

738

739

740

741

ALE meta-analyses of functional neuroimaging in AWS during speech tasks show overactivation in areas corresponding to motor activity and underactivation in areas corresponding to auditory activity (Budde et al., 2014; Belyk et al., 2015; see state/trait comparisons in these meta-analyses for additional areas and finer granularity). Cerebellar vermis in AWS is underactive compared to controls, but overactive during stuttering. Neuroimaging of children who stutter shows differences from controls in several of the areas identified for adults who stutter (see, for example, Garnett et al., 2018; Kronfeld-Duenias et al., 2018; Koenraads et al. 2020), suggesting that the neurodevelopmental trajectory for stuttering diverges from that of ordinarily fluent speakers close to stuttering onset.

The core hypotheses of reflexivity and communicative mismatch will be traced through the brain areas just described. The route followed will describe a chronological sequence from audition of own voice, through cortical activity consistent with an ongoing speech act, to the creation of observable stuttering via speech-motor activity. References are as per the review articles already cited (Etchell et al., 2017, Neef et al., 2015, Belyk et al., 2015 and Budde et al., 2014) with further references introduced as necessary.

According to the Concurrency Hypothesis (section 2), own voice will be identified through coincidence detection between cochlear and vestibular afferents. Only two studies have assessed the vestibular system in PWS. Langová et al. (1975) found that horizontal nystagmus evoked during speech is more pronounced in PWS than in controls using rotary chair testing. Gattie et al. (submitted) found the vestibular-evoked myogenic potential, an indirect functional test of the vestibular brainstem and periphery, is smaller in PWS than in controls. The suggestion is of divergence in central vestibular function, and/or the nature of conduction along the VIII cranial nerve, between PWS and controls. Interpreted according to the Concurrency Hypothesis (section 2.3.2), a smaller vestibular input to the auditory brainstem would correspond to a lower likelihood for coincidence detection in cells whose excitation depends upon summation of synaptic input from multiple fibres (e.g. octopus cells in the cochlear nucleus, or principal cells of the medial superior olivary complex; Golding \& Oertel, 2012). It follows that the ascending auditory stream at later stages of the ascending auditory pathway, or in temporal cortex, will be more weakly identified as an own voice stream in PWS than in controls. Inputs to cerebellar vermis will also be reduced during vocalisation for PWS (i.e. as per figure 3 ).

The sum of activity so far (smaller vestibular input to afferent streams of neural activity through the cerebellum and auditory brainstem) would more weakly identify own voice in PWS than in ordinarily fluent speakers. This occurs because the coincidence detection proposed by the Concurrency Hypothesis will be weaker with a smaller vestibular input. The weaker identification of own voice would in turn correspond to the increased reflexivity hypothesised for PWS. It is almost as if own voice is interpreted as for the voice of another speaker. From a systems control perspective (e.g. as per Jones et al., 2016), this would be referred to as inadequate sensory gating of the own voice auditory stream.

In the cerebrum, afferent own voice streams mediated via auditory brainstem and cerebellum could alter function in two brain areas which have repeatedly been identified as important in stuttering research. One of these is the cortico-basal ganglia-thalamo-cortical loop (Milardi et al., 2019), which is reviewed specifically in relation to stuttering by Chang \& Guenther (this issue). The other area is temporal cortex, and in particular the temporo-parietal junction. Recall in this regard the discussion of section 2.4.1, that 
an own voice auditory stream would provide a target for the proposed efference copy of the speech plan in predictive feedback control models. Several authors have proposed that a difference in such moderation, or in auditory-motor mapping, between PWS and controls underlies the observed stuttering behaviour (Max et al., 2004; Brown et al., 2005; Hickok et al., 2011; Cai et al., 2012). The proposals have received little support in direct tests (e.g. Beal et al., 2010; Liotti et al., 2010). However, tests have used vocalisation versus $A C$ playback protocols. As described in section 2.4.1, vocalisation versus AC playback protocols do not use a physiologically valid own voice stimulus in the playback condition, and as such do not evaluate speech-induced suppression. Accordingly, the proposal that moderation of temporal cortex by speech-motor activity differs between PWS and controls remains live. It is one of the possibilities for the hypotheses of concurrency and reflexivity when applied to stuttering via a predictive feedback control model. Investigation of the temporo-parietal junction is of particular interest, because it has repeatedly been identified as important for self-other distinction (Steinbels, 2016), and contains an area in the Sylvian fissure hypothesised as important for language control (Hickok, 2017). The role of the cerebellum may also be crucial. The cerebellum is repeatedly found to have involvement in speech perception (meta-analysis in Skipper \& Lametti, 2021). This includes high level tasks involving semantics, grammar, and comprehension (Ackermann \& Brendel, 2016; Mariën \& Manto, 2015).

The hypothesis of communicative mismatch is based on approach-avoidance conflict (Sheehan 1953; 1958; 1970; 1975), which contemporary research (review in Aupperle \& Paulus, 2010; Barker et al., 2019) places in the insula, amygdala, prefrontal cortex and the basal ganglia. All of these areas have been identified as showing a difference between PWS and controls in neuroimaging research (Yang et al., 2017; Toyomura et al., 2018; Budde et al, 2014; Etchell et al., 2017; see Garcia-Barrera \& Davidow, 2015, for discussion of connection between prefrontal and anterior cingulate cortex in error monitoring). The basal ganglia in particular are crucial to the hypothesis of communicative mismatch. This is because conflict between selection and inhibition of competing actions, sometimes termed as "Go" and "No Go" (Mink, 1996; Bahuguna et al., 2015; Dunovan et al., 2015; Mink, 2018), could create involuntary muscular activity similar to that observed in stuttering. Thus, following the sequence described in this section from audition to articulation, basal ganglia activity would be the most proximal cause of observable stuttering behaviour (see Arenas, 2017, for a proposal emphasising functional importance of the subthalamic nucleus). Frontal and parietal cortex associated with speech-motor control would show state and trait differences in stuttering due their involvement in basal ganglia pathways (Albin et al., 1989; DeLong et al, 1990; Calabresi et al., 2014), and also due to white matter connection to temporal cortex important for auditory-motor integration (e.g. the efference copy proposed in speech-motor models), including commissural connection to homologues. The basal ganglia and cerebellum are interconnected via the thalamus (Hoshi et al., 2005; Bostan et al., 2010, Pelzer et al., 2017; Caligiore et al., 2017; Cacciola et al., 2017; Bostan \& Strick, 2018) and are both proposed to have involvement in language processing and vocal learning (Booth et al., 2007; Pidoux et al., 2018). This underscores the prospective importance of the vestibular-cerebellar pathway (figure 3 ) for own voice identification in stuttering, and of cerebellar input to the cortico-basal ganglia-thalamo-cortical loop in stuttering (Chang \& Guenther, this issue). Dopamine levels in the basal ganglia affect action selection (Mink, 1996; Reynolds et al., 2001; Haber, 2014; Schultz, 2016), with differences in the dopamine system between PWS and controls found using positron electron tomography (Wu et al., 1997) and through pharmaceutical intervention (Maguire et al., this issue). The basal ganglia have been repeatedly identified as important in stuttering research (Alm, 2004; Metzger et al., 2017; Chang \& Guenther, this issue).

\subsubsection{Stuttering subtypes}

The neurological substrate described in the previous section encompasses almost the entire brain. This raises the possibility that preconditions for stuttering may require a difference from ordinarily fluent 
speakers in the function of not just one brain area, but several (ie. as per Ludlow \& Loucks, 2003). Such a view underlies multifactorial models of stuttering (e.g. Smith \& Kelly, 1997; Starkweather, 2002; Walden et al., 2012; Smith \& Weber, 2017), which examine the interplay between genetic, organismic and environmental contributing factors.

One way to develop such models would be through subtyping stuttering. If there are discrete groupings of factors which contribute to stuttering, separation into such groupings prior to data analysis could enable more granular investigation and facilitate hypothesis formulation. Unfortunately, subtyping stuttering is difficult (see review in Yairi, 2007; Seery et al., 2007), largely due to the challenges of longitudinal data collection.

Subtyping is proposed here, based on the four track system of Van Riper (1973; 1982 p94-108). Symptomatology is identical to that of Van Riper, but the account is extended with the proposal that causation differs between tracks. Track I is proposed to correspond to stuttering developing as an isolated diagnosis. Track II corresponds to stuttering co-developing with at least one other diagnosis. Tracks III and IV are trauma-based, and may be psychogenic or neurogenic.

Track I would have a genetic basis and be based around increased reflexivity. The genetic basis may affect several brain areas (i.e. as per Ludlow \& Loucks, 2003). For example, genetic investigation of stuttering has suggested that the nature of white matter may be integral to stuttering behaviour lyosomal pathways or glial cells are implicated (Han et al., 2019; Benito-Aragón et al. 2020). PWS have reduced fractional anisotropy in dorsal white matter tracts which connect cortical regions having speechmotor and auditory function (Neef et al., 2015; Etchell et al., 2017). It would appear that genetic variations in stuttering might be connected to the structure of these dorsal white matter tracts. If so, it is not clear why the white matter structural variation should be focal to just these dorsal tracts (Watkins \& Büchel, 2010; Drayna, 2010). One possibility is that genetic variation affects several white matter tracts. It may, for example, also manifest as reduced fractional anisotropy in the vestibular portion of the VIII cranial nerve. If so, the variation would be consistent with the finding of a weaker vestibular response in PWS by Gattie et al. (submitted), and would support interpretation according to the concurrency and reflexivity hypotheses presented in the current article.

This suggestion around genetics is just one example of a long-term investigative target for stuttering research. Many other possibilities pertain - not only variations within the neurological substrate described for stuttering in section 3.4.1.1, but moreover the interplay between genetic, organismic and environmental factors described in multifactorial models of stuttering. Investigation of which factors are necessary and/or sufficient for behavioural stuttering to manifest is a topic for ongoing research.

From this perspective, track II stuttering is a particular version of track I in which one of the variations contributing to the co-occurring diagnosis also contributes to stuttering behaviour. The existence of track II stuttering would explain why stuttering co-occurs with other diagnoses at a rate higher than chance. Depending on the nature of co-occurring diagnoses (and accepting that co-occurring diagnoses will sometimes remain pending) existence of track II stuttering could also explain why testing groups of PWS sometimes results in a subtle difference from controls in abilities such as executive function, language, reaction time and general motor control. The explanation would be that a co-occurring diagnosis, rather than stuttering, is causative of the test result. Such a distinction has been established in studies which split the PWS group into those with and without a co-occurring diagnosis (e.g. Cullinan \& Springer, 1980; Liebetrau \& Daly, 1981; McKnight \& Cullinan, 1987; Kobayashi \& Hayasaka, 2003) 
REMATCH places stuttering at the semantic-pragmatic interface, but is compatible with the psycholinguistic models introduced in section 3.2.3.1. Application of the psycholinguistic models will help to distinguish tracks I-IV. Stuttering in tracks I and II could be described by a combination of EXPLAN (Howell, 2004; 2008) and the Variable Release Threshold hypothesis (Brocklehurst et al., 2013). It is suggested here that the account is updated such that it is REMATCH, rather than the compatible but less detailed anticipatory struggle hypothesis of Bloodstein (1975), which provides detail of the release threshold.

Tracks III and IV stuttering are proposed as having a trauma-based origin which could be psychogenic or neurogenic. When the trauma results in heightened self-awareness (Gallagher \& Zahavi, 2021; Smith, 2020) increased attention to self-monitoring would follow. From the perspective of REMATCH the increased attention to self-monitoring would equate to increased reflexivity through a route other than the auditory system. Essentially, there is increased self-doubt about any speech act. In some cases the trauma could follow a profound emotional event (e.g. a bereavement or a family break-up), but it could also follow a more subtle series of events (Starkweather, 2002, lists possible environmental influencers on stuttering). Such stuttering could be described by the Vicious Circle Hypothesis (Vasić \& Wijnen, 2005), in which monitoring of phonological error becomes hyper-vigilant. This type of stuttering could alternatively be explained from the perspective of EXPLAN and the Variable Release Threshold hypothesis. It would correspond to a release threshold which varies similarly to that of an ordinarily fluent speaker, but which is continuously subject to a multiplier greater than unity.

Other instances of tracks III and IV could be primarily caused by neural insult (e.g. transient ischemic attack, traumatic brain injury or neurodegenerative disease). If the effect of the neural insult is to alter function of a brain area important for phonological formulation, this type of stuttering could be described by the Covert Repair Hypothesis. However, neurogenic stuttering will be the most difficult to model. If the diagnosis is of a progressive neurological condition, stuttering may be transient prior to being masked by a wider range of symptoms involving language, speech-motor or executive function. In neurogenic stuttering with no other symptoms, behaviour may differ from tracks I-II due to the alteration in brain function having a random structural cause (neural insult) rather than proceeding through a genetic, developmental or psychological route.

Tracks I-IV may show overlap. For example, a child may have a genetic disposition to stuttering (track I) and experience environmental conditions creating psychosocial pressure (track III). This notion underlies the Demands and Capacities model (Adams, 1990; Starkweather \& Gottwald, 1990; Starkweather, 2002), which is frequently interpreted as a genetic predisposition to stuttering becoming concrete following environmental influence. However, the predisposition need not be genetic; combinations of any of tracks I-IV, and/or single track etiologies, could just as well result in stuttering behaviour.

864

865

866

867

868

869

870

871

Developmental stuttering could involve any of tracks I-IV. Whereas absence of a plausible genetic or developmental contributory mechanism to stuttering in adulthood seems to limit adult onset stuttering to tracks III and IV. Thus, the rarity of adult onset stuttering (Ward, 2006, ch 16) is consistent with Van Riper's $(1973$; 1982) finding that between $80-90 \%$ of his 300 -strong caseload were tracks I or II. An exception would be adult onset where there is a history of childhood stuttering (Van Riper, 1982 p66). In such cases, reappearance may have psychogenic or neurogenic influence. For example, Shahed \& Jankovic (2001) describe 12 persons who had stuttered in childhood but not as adults, and for whom stuttering reappeared following a diagnosis of Parkinson's disease. 


\subsubsection{Other explananda}

The following sections address the explananda in tables 2 and 3 , to which the reader might simultaneously refer.

\subsubsection{Linguistic and Situational}

Variation in phonological formulation between stuttering subtypes was described in section 3.4.2. However, the main linguistic hypothesis within REMATCH is that own speech is interpreted in PWS with increased salience. Recall now the explananda in table 2 . Unconscious processes are proposed to block an ongoing utterance whenever there is uncertainty about a speech act. Uncertainty is proposed to increase with propositionality, and hence stuttering will correlate with propositionality. Without an audience, a speech act cannot be performed. This explains why, unless PWS project an audience, stuttering will not occur when alone (Langová \& Sváb, 1973). With authority listeners, even ordinarily fluent speakers experience increased salience when executing a speech act. For PWS, increased salience due to the authority listener combines with increased salience due to reflexivity, increasing the propensity for stuttering according to REMATCH.

These proposals are consistent with the observation of Sheehan (1958) that speech breakdown in stuttering coincides with the requirement "to say something important to someone important". The proposals could be tested by following theoretical frameworks for pragmatics and social convention (e.g. Grice. 1957, 1989; Rescorla, 2019). For example, the exact loci of stuttered instances could be a project in experimental pragmatics (Noveck \& Sperber, 2004; Meibauer \& Steinbach, 2011; Noveck, 2018). Such a project might initially appear circular (stuttered phonemes are predefined as those with high propositionality). However, corpora of stuttered speech provide rich data, and can therefore be investigated following themes in pragmatics (e.g. Gricean implicatures, epistemic vigilance) using statistical techniques such as latent class or principal components analysis. Such an approach could also appraise changes in language use with development (e.g. within people who stutter there is a tendency for children to stutter on function words, and adults to stutter on content words). See also Eisenson \& Horowitz (1945), Sheehan et al. (1967), Gould \& Sheehan (1967) and MacKay (1969) for examples of work which could fit within a research programme for experimental pragmatics in stuttering.

\subsubsection{Anticipation, Consistency and Adjacency}

Speakers can unconsciously scan ahead. This applies to spontaneous speech or when reading aloud. If message content scanned ahead is interpreted by the speaker according to REMATCH, the person who stutters will be able to predict when speech difficulty is imminent. In oral readings, uncertainty around any particular word is unchanged on repeated readings, because the underlying message has not changed. Therefore, stuttering has the same loci on repeat readings. When words are blotted out, the reader unconsciously anticipates what the word would have been (or infers intended meaning from the words remaining) leading to stuttering on the word that is unconsciously predicted to convey intended meaning to a listener. This will usually be an adjacent word to the word previously stuttered.

\subsubsection{Adaptation}

Propositionality is reduced on repeat readings, since the listener is already aware of the message being delivered, and the speaker is aware of the message as well. Reduced propositionality in turn reduces salience. According to REMATCH, reduced salience will reduce the tendency for the speaker to unconsciously block an ongoing speech act. Essentially, reduced propositionality acts as a counter for the increased reflexivity proposed in PWS. 


\subsubsection{Operant Conditioning}

Speech-motor or psycholinguistic breakdown accounts of stuttering appeal to emotional or psychosocial stress to explain situational variation. A problem for such accounts is that they predict that stress should be very high in laboratory conditions with response-contingent stimulation (e.g. electric shock or time out upon stuttering), and therefore stuttering should increase. However, the converse is found: stuttering decreases with response-contingent stimulation.

The finding can be explained by REMATCH as response-contingent stimulation forcing an attentional shift in the speaker. The attentional shift is towards an increased conscious control of speech. This shift diminishes the influence of unconscious processing of speech, which according to REMATCH (figure 7) will reduce the amount of stuttering. Increasing conscious control is sufficiently effortful that unless an operant speaking technique such as fluency shaping has been learnt, PWS will not increase conscious control volitionally (see Constantino et al., 2020, for extended discussion). However, the continuous presence of response-contingent stimulation in laboratory conditions makes increased conscious control of speech unavoidable for the speaker.

\subsubsection{Alterations to audition during speech}

Alterations to audition during speech will affect own voice identification according to the Concurrency Hypothesis (section 2). Alterations which are effective are proposed to reduce reflexivity, and thereby to reduce stuttering according to REMATCH. The exact detail of audition changes effective for reducing stuttering is a topic for ongoing research. Timings in table 1 show a starting point. The effectiveness of long delays (e.g. $50 \mathrm{~ms}$ or more) may have more to do with phoneme or syllable recognition, or word recognition, than with own voice identification. If so, effectiveness of particular delay lengths will be variable, because the duration of word-initial phonemes is variable. The prediction from the Concurrency Hypothesis is that alterations on the time scale of a millisecond or less will be most effective. Such rapid alterations have not been tested other than by Howell et al. (1987), who showed that frequency shifts with a delay on the order of one millisecond were more effective at reducing stuttering than delays of 50 ms. Alterations most effective for reducing stuttering may depend on individual physiologies. If so, there is a prospect for tailoring the delay to individuals depending on EEG measurements. Such a project would be a part of, or be informed by, the investigation of own voice identification outlined in section 2 .

In alterations to audition involving a second speaker (shadowing or unison speaking) there is an additional benefit in that propositionality is also reduced (the second speaker is already aware of the message being delivered, and is encouraging delivery of that message). For this reason, unison speaking is the most effective way of reducing stuttering.

\subsubsection{Therapy effectiveness} REMATCH identifies the proximal cause of core stuttering behaviour as simultaneous "Go" and "No Go" signals in brain areas coordinating articulatory muscles, as described in section 3.4.1.1. Accessory and interiorised stuttering behaviours are explained in this regard as attempts by the speaker to resolve core stuttering behaviours (i.e. explanation as per Van Riper, 1982, ch 6-7).

Early stages of many stuttering therapies (e.g. the motivation, identification and desensitisation stages described by Van Riper, 1973) include psychological therapy, helping speakers to unlearn accessory and interiorised stuttering behaviours which have become engrained through habit. These early stages of stuttering therapy increase approach and decrease avoidance behaviours. For example, desensitisation therapy reduces emotionality attached to speaking situations. It is proposed that reduced emotionality will decrease the tendency to unconsciously block an ongoing speech act, and increase willingness to speak. The effect would be to reduce reflexivity, and thereby decrease stuttering according to REMATCH. 
Speech work in therapies (e.g. the variation and adaptation stages in Van Riper, 1973) deliberately introduces prolongation to the beginning of syllables. Prolongation acts similarly to an alteration to audition during speech, and thereby reduces stuttering as described in section 3.4.2.5. An alternative strategy having the same effect would be to deliberately introduce repetition (Johnson. 1961). However, deliberate repetition is seldom used, perhaps because it is more noticeable than prolongation.

A major distinction between therapies is whether prolongation is on every syllable (fluency shaping) or only on syllables where stuttering is anticipated (block modification). See discussion in Ingham (1984, p328) or Gregory (1979). Prolongation on every syllable entails a continued attentional shift whilst talking. According to REMATCH, continued attentional shift will reduce stuttering (see section 3.4.2.4). Thus, fluency shaping has two methods reducing the amount of stuttering: syllable initial prolongation, and attentional shift. This would explain why fluency shaping programmes are often more effective than block modification programmes in reducing the amount of stuttering. However, fluency shaping programmes are effortful for the speaker (Constantino, 2020) and for this reason many PWS will prefer a block modification approach.

\subsection{Discussion of the REMATCH hypothesis}

The REMATCH hypothesis draws together breakdown and anticipatory struggle hypotheses of stuttering. In this sense, it is similar to, and compatible with, the Variable Release Threshold hypothesis of Brocklehurst et al. (2013). REMATCH goes into additional detail by specifying that the type of anticipatory struggle is an updated version of the approach-avoidance conflict proposed by Sheehan $(1953 ; 1958$; $1970 ; 1975)$. This update situates REMATCH in what Levelt $(1989,1999)$ refers to as the Conceptualiser. Thus, REMATCH is fundamentally different from (although compatible with) hypotheses which explain stuttering as breakdown in what Levelt refers to as the Formulator and/or Articulator. From this perspective, a major contribution of REMATCH is to provide a framework through which psycholinguistic and situational variation in stuttering can be investigated.

The updated approach-avoidance conflict in REMATCH is explained through a view of the unconscious proposed to be similar to that in dual process theory (e.g. as per Evans, 2007; Kahneman, 2011), and containing a high degree of automaticity. This provides a basis for investigation using cognitive science methodologies (e.g. as per the experimental pragmatics of Noveck \& Sperber, 2004). The unconscious process in REMATCH could just as well have been explained as an update of repressed needs hypotheses of stuttering, in which the view of the unconscious is no longer necessarily that of psychoanalytic theory. This is possible because REMATCH contains a description of the moment of stuttering (figure 7) which can be compared to and informed by first person accounts. Thus, REMATCH promotes integration of qualitative and quantitive work in stuttering, and can furthermore provide a link to phenomenological accounts of stuttering (e.g. Ellis, 2020; Isaacs, 2020). Such integrations could inform psychological therapies for stuttering. They could also help to promote a social model of stuttering (Campbell et al., 2019), even within a world where neuroscientific research will remain within a medical model. Efforts in this direction are important if stuttering research is to be relevant to people who stutter.

\section{General discussion}

This article has described hypotheses of own voice identification and stuttering. The account has been highly detailed and with very broad scope because, as described in section 1 , all of the hypotheses are proposed together as a best explanation argument. As such, it is necessary to show that the combined explanation has a high degree of explanatory power and parsimony. 
The crux of this article is the Concurrency Hypothesis that own voice is identified through coincidence detection between the neural firing rates arising from deflection of cochlear and vestibular mechanoreceptors by the sound and vibration generated during vocalisation. Section 2 describes how the Concurrency Hypothesis provides a principled basis for self-environment distinction, with importance for considerations in cognitive science and philosophy of mind. The Concurrency Hypothesis was also applied to speech-motor research, in which it highlighted limitations in empirical support for the proposal that speech-motor activity modulates activity in temporal cortex. Finally, the Concurrency Hypothesis was applied to auditory scene analysis, in which it is proposed to provide the basis for a system of discrimination in multi-talker scenarios.

In section 3, the Concurrency Hypothesis was developed into an explanation of stuttering. The initial step was to propose a quale, reflexivity. This refers to the phenomenology of hearing one's own voice, and is proposed to differ between people who do and do not stutter. The account was then developed into an update of the approach-avoidance conflict model of stuttering (Sheehan 1953; 1958; 1970; 1975), referred to as REMATCH. This explains the moment of stuttering as a communicative mismatch. The speaker experiences own voice with increased salience, but this creates a mismatch whenever there is uncertainty about the ongoing message. In such cases, unconscious processes reinterpreting the message create nerve signals blocking the ongoing speech act, at the same time the speaker is consciously trying to continue. The resultant conflict is behaviourally observable as stuttering.

The Concurrency Hypothesis and REMATCH are core hypotheses. Many auxiliary hypotheses were introduced, mainly within the account of stuttering. These include the neurological substrate for stuttering, a proposal for subtyping stuttering, and a variety of process and contrastive explanations of data from stuttering research. These auxiliary hypotheses are likely to change with time, and are provided here as a snapshot so that the scope of the intended explanation of stuttering is apparent.

The Concurrency Hypothesis could be applied groups other than people who stutter, and who are expected to show differences from controls in own voice identification. Some examples of such groups include those experiencing auditory and/or vestibular neuropathy (Kaga, 2016) and those experiencing auditory hallucination (e.g. in schizophrenia - McLachlan, Phillips, Rossell \& Wilson, 2013; Matthews et al., 2013; Weintraub et al., 2012; Waters \& Fernyhough, 2019).

Testable predictions generated by the hypotheses in this article are described in sections 2 and 3 . One of these predictions is that people who stutter should show a difference from controls in tests of the vestibular system. This was appraised by Gattie et al (submitted) with the finding that vestibular response is weaker in people who stutter than in paired controls. The result is consistent with the only prior research on the vestibular system in people who stutter (Langová et al., 1975) and supports the hypotheses presented in this article.

\section{Conclusion}

The major recommendation from this article is that researchers should use physiologically valid stimuli when investigating own voice in speech and language research. Using stimulation over air conduction only, even with a sound pressure level increase to perceptually match the loudness experienced during vocalisation, does not generate physiologically valid stimuli. Instead, stimuli should consist of a combination of air conducted sound and body conducted vibration which is binaurally symmetric, and has coincident arrival at both inner ears. 


\section{Conflict of Interest}

1042 The authors declare that the research was conducted in the absence of any commercial or financial 1043 relationships that could be construed as a potential conflict of interest.

1044

1045

1046

1047

1048

1049

1050

1051

1052

1053

1054

1055

1056

1057

1058

1059

1060

1061

1062

1063

1064

1065

1066

1067

1068

1069

1070

1071

1072

1073

1074

1075

1076

\section{Author Contributions}

Conceptualization: ideas; formulation of the overarching research goals and aims

MG

Methodology: development or design of methodology or creation of models

MG

Software: programming; software development; designing computer programs; implementation of computer code or algorithms; testing code components

MG

Validation: verification of the replication and reproducibility of results, experiments, or other research outputs

MG

Formal analysis: application of statistical, mathematical, computational, or other techniques to analyse or synthesise data

MG

Investigation: conducting the research and investigation process, specifically performing the experiments or data collection

MG

Resources: provision of study materials, materials, instrumentation, computing resources, or analysis tools

MG

Data curation: annotation, scrubbing, or maintenance of research data (including software code, where it is necessary for interpreting the data itself)

MG

Writing-original draft: preparation, creation and/or presentation of the published work, specifically writing the initial draft

MG

Writing - review \& editing: critical review, commentary, or revision

$M G, K K, E L$

Visualization: preparation, creation and/or presentation of the published work, specifically data presentation or visualisation

MG

Supervision: oversight and leadership responsibilities, including mentorship

$\mathrm{KK}, \mathrm{EL}$ 
Project administration: coordination of the research activity planning and execution

MG, KK, EL

1079 Funding acquisition: acquisition of financial support

1080 MG, KK

1081

1082

1083

1084

1085

1086

1087

\section{Funding}

This work was supported by a UK Economic and Social Research Council (ESRC) Collaborative Award in Science and Engineering (CASE) to Max Gattie. The CASE partner was Interacoustics A/S, Middelfart, Denmark. Karolina Kluk was supported by NIHR Manchester Biomedical Research Centre.

\section{Acknowledgments}

Thanks to Paul Brocklehurst for comments on this article. Any shortcomings in the finished article are solely the responsibility of the named authors.

\section{References}

Abdalla, S. (2011). Low Frequency Dielectric Properties of Human Blood. IEEE Transactions on NanoBioscience, 10(2), 113-120. http://doi.org/10.1109/TNB.2011.2159734

Acheson, D. J., \& Hagoort, P. (2014). Twisting tongues to test for conflict-monitoring in speech production. Frontiers in Human Neuroscience, 8, 206. http://doi.org/10.3389/fnhum.2014.00206

Ackermann, H., \& Brendel, B. (2016). Cerebellar contributionsto speech and language. In G. Hickok \& S. L. Small (Eds.), Neurobiology of language(pp. 73-84). Academic Press. https://doi.org/10.1016/B978-012-407794-2.00007-9

Adams, J. C. (1997). Projections from octopus cells of the posteroventral cochlear nucleus to the ventral nucleus of the lateral lemniscus in cat and human. Aud. Neurosci. 3, 335-350.

Adams, M. R. (1990). The Demands and Capacities Model I: theoretical elaborations. Journal of Fluency Disorders, 15, 136-141.

Agmon-Snir, H., Carr, C. E., \& Rinzel, J. (1998). The role of dendrites in auditory coincidence detection. Nature, 393(6682), 268-272. http://doi.org/10.1038/30505

Ajdacic-Gross, V., Vetter, S., Müller, M., Kawohl, W., Frey, F., Lupi, G., et al. (2010). Risk factors for stuttering: a secondary analysis of a large data base. European Archives of Psychiatry and Clinical Neuroscience, 260(4), 279-286. http://doi.org/10.1007/s00406-009-0075-4

Ajdacic-Gross, V., Bechtiger, L., Rodgers, S., Müller, M., Kawohl, W., Känel, von, R., et al. (2018). Subtypes of stuttering determined by latent class analysis in two Swiss epidemiological surveys. Plos One, 13(8), e0198450. http://doi.org/10.1371/journal.pone.0198450

Alexander, G.E., Newman, J.D. and Symmes, D. (1976), Convergence of prefrontal and acoustic inputs upon neurons in the superior temporal gyrus of the awake squirrel monkey. Brain Res., 116 334-338.

Alm, P. A. (2004). Stuttering and the basal ganglia circuits: a critical review of possible relations. Journal of Communication Disorders, 37(4), 325-369. http://doi.org/10.1016/j.jcomdis.2004.03.001

Albin, R.L., Young, A.B. \& Penney, J.B. (1989). The functional anatomy of basal ganglia disorders. Trends Neurosci. 12, 366-375.

Ambrose, N. G., Cox, N. J., \& Yairi, E. (1997). The genetic basis of persistence and recovery in stuttering. Journal of Speech, Language, and Hearing Research : JSLHR, 4O(3), 567-580. http://doi.org/10.1044/js/hr.4003.567

Andrews G. \& Harris M. (1964) The Syndrome of Stuttering. London, UK: Spastics Society Medical Education and Information Unit in association with Heinemann Medical.

Andrews, G., Craig, A., Feyer, A.-M., Hoddinott, S., Howie, P., \& Neilson, M. (1983). Stuttering: A review of research findings and theories circa 1982. Journal of Speech and Hearing Disorders, 48, 226-246. 
Arenas, R. M. (2017). Conceptualizing and investigating the contextual variability of stuttering: The speech and monitoring interaction (SAMI) framework. Speech, Language and Hearing, 20(1), 15-28. http://doi.org/10.1080/2050571X.2016.1221877

Arend, J. M., Stade, P., \& Pörschmann, C. (2017). Binaural reproduction of self-generated sound in virtual acoustic environments (pp. 015007-15). Presented at the 173rd Meeting of Acoustical Society of America and 8th Forum Acusticum, Acoustical Society of America. http://doi.org/10.1121/2.0000574

Arndt, J., \& Healey, E. C. (2001). Concomitant disorders in school-age children who stutter. Language, Speech, and Hear- ing Services in Schools, 32, 68-78.

Ashida, G., \& Carr, C. E. (2011). Sound localization: Jeffress and beyond. Current Opinion in Neurobiology, 21(5), 745-751. http://doi.org/10.1016/j.conb.2011.05.008

Atencio, D. J., \& Montero, I. (2009). Private speech and motivation: The role of language in a sociocultural account of motivational processes. In A. Winsler, C. Fernyhough, \& I. Montero (Eds.), Private speech, exec- utive functioning, and the development of verbal self-regulation (pp. 201-223). Cambridge, UK: Cambridge University Press. http://dx.doi .org/10.1017/CBO9780511581533.017

Aupperle, R. L., \& Paulus, M. P. (2010). Neural systems underlying approach and avoidance in anxiety disorders. Dialogues in Clinical Neuroscience, 12(4), 517-531. http://doi.org/10.31887/DCNS.2010.12.4/raupperle

Bahuguna, J., Aertsen, A., \& Kumar, A. (2015). Existence and control of Go/No-Go decision transition threshold in the striatum. PLoS computational biology, 11(4), e1004233. https://doi.org/10.1371/iournal.pcbi.1004233

Bajo, V. M., \& King, A. J. (2012). Cortical modulation of auditory processing in the midbrain. Frontiers in Neural Circuits, 6, 114. http://doi.org/10.3389/fncir.2012.00114

Barker, M., Solinski, H. J., Hashimoto, H., Tagoe, T., Pilati, N., \& Hamann, M. (2012). Acoustic overexposure increases the expression of VGLUT-2 mediated projections from the lateral vestibular nucleus to the dorsal cochlear nucleus. Plos One, 7(5), e35955. http://doi.org/10.1371/journal.pone.0035955

Barker, T. V., Buzzell, G. A., \& Fox, N. A. (2019). Approach, avoidance, and the detection of conflict in the development of behavioral inhibition. New Ideas in Psychology, 53, 2-12. http://doi.org/10.1016/j.newideapsych.2018.07.001

Barber, V.B. (1939) Studies in the psychology of stuttering: XV. Chorus reading as a distraction in stuttering. Journal of Speech Disorders, 4, 371-383.

Barber, V.B. (1940) Studies in the psychology of stuttering: Rhythm as a distraction in stuttering. Journal of Speech Disorders, 5, 29-42.

Barr, D. J., Levy, R., Scheepers, C., \& Tily, H. J. (2013). Random effects structure for confirmatory hypothesis testing: Keep it maximal. Journal of Memory and Language, 68, 255-278. http://dx.doi.org/ 10.1016/j.jml.2012.11.001.

Bates, D., \& Maechler, M. (2009). Ime4: Linear mixed-effects models using S4 classes.

Baumgartner, J., \& Duffy, J. R. (1997). Psychogenic stuttering in adults with and without neurologic disease. Journal of Medical Speech-Language Pathology, 5(2), 75-95.

Baxter, S., Johnson, M., Blank, L., Cantrell, A., Brumfitt, S., Enderby, P., \& Goyder, E. (2015). The state of the art in non-pharmacological interventions for developmental stuttering. Part 1: a systematic review of effectiveness. International Journal of Language \& Communication Disorders, 50(5), 676-718. http://doi.org/10.1111/1460-6984.12171

Beal, D. S., Cheyne, D. O., Gracco, V. L., Quraan, M. A., Taylor, M. J., \& De Nil, L. F. (2010). Auditory evoked fields to vocalization during passive listening and active generation in adults who stutter. Neurolmage, 52(4), 1645-1653. http://doi.org/10.1016/j.neuroimage.2010.04.277

Behroozmand, R., Shebek, R., Hansen, D. R., Oya, H., Robin, D. A., Howard, M. A., \& Greenlee, J. D. W. (2015). Sensory-motor networks involved in speech production and motor control: an fMRI study. Neurolmage, 109(C), 418-428. http://doi.org/10.1016/j.neuroimage.2015.01.040

Beiderbeck, B., Myoga, M. H., Müller, N. I. C., Callan, A. R., Friauf, E., Grothe, B., \& Pecka, M. (2018). Precisely timed inhibition facilitates action potential firing for spatial coding in the auditory brainstem. Nature Communications, 9(1), 1771-13. http://doi.org/10.1038/s41467-018-04210-y 
von Békésy, G. (1949). "The structure of the middle ear and the hearing of one's own voice by bone conduction," J. Acoust. Soc. Am. 21, 217-232.

Benito-Aragón, C., Gonzalez-Sarmiento, R., Liddell, T., Diez, I., d'Oleire Uquillas, F., Ortiz-Terán, L., et al. (2020). Neurofilament-lysosomal genetic intersections in the cortical network of stuttering. Progress in Neurobiology, 184, 101718. http://doi.org/10.1016/j.pneurobio.2019.101718

Beving, H., Eriksson, L. E., Davey, C. L., \& Kell, D. B. (1994). Dielectric properties of human blood and erythrocytes at radio frequencies $(0.2-10 \mathrm{MHz})$; dependence on cell volume fraction and medium composition. European Biophysics Journal : EBJ, 23(3), 207-215.

BinKhamis, G., A. Léger, S. L. Bell, G. Prendergast, M. O’Driscoll, and K. Kluk. 2019. "Speech Auditory Brainstem Responses: Effects of Background, Stimulus Duration, Consonant-Vowel, and Number of Epochs." Ear and Hearing 40(3): 659-670. doi:10.1097/AUD.0000000000000648.

Blood, G. W., Ridenour, V. J., Jr, \& Qualls, C. D. (2003). Co-occurring disorders in children who stutter. Journal of Communication Disorders, 36, 427-448.

Bloodstein, O. (1995) A Handbook on Stuttering (5th ed), Singular.

Bloodstein, O. (2002). Early stuttering as a type of language difficulty. Journal of Fluency Disorders, 27(2), 163-6- quiz 166-7. http://doi.org/10.1016/s0094-730x(02)00111-0

Bloodstein, O. (2006). Some empirical observations about early stuttering: a possible link to language development. Journal of Communication Disorders, 39(3), 185-191.

http://doi.org/10.1016/j.jcomdis.2005.11.007

Boulet, S. L., Boyle, C. A., \& Schieve, L. A. (2009). Health care use and health and functional impact of developmental disabil- ities among US children, 1997-2005. Archives of Pediatrics \& Adolescent Medicine, 163, 19-26.

Booth JR, Wood L, Lu D, Houk JC, Bitan T (2007). The role of the basal ganglia and cerebellum in language processing. Brain Res.;1133:136-44.

Bregman, A. S. (1990) Auditory scene analysis. MIT Press: Cambridge, MA

Briley, P.M. \& Ellis, C. Jr (2018). The Coexistence of Disabling Conditions in Children Who Stutter: Evidence From the National Health Interview Survey. J Speech Lang Hear Res.;61(12):2895-2905. doi: 10.1044/2018_JSLHR-S-17-0378.

British Society of Audiology (2012), Recommended Procedure: Cervical and Ocular Vestibular Evoked Myogenic Potentials

Brown, S., Ingham, R. J., Ingham, J. C., Laird, A. R., \& Fox, P. T. (2005). Stuttered and fluent speech production: An ALE meta-analysis of functional neuroimaging studies. Human Brain Mapping, 25(1), 105-117. http://doi.org/10.1002/hbm.20140

Brown, T., Sambrooks, J. E., \& MacCulloch, M. J. (1975). Auditory thresholds and the effect of reduced auditory feedback of suttering. Acta Psychiatrica Scandinavica, 51(5), 297-311. http://doi.org/10.1111/j.1600-0447.1975.tb00009.x

Buchsbaum, B. R., Hickok, G., \& Humphries, C. (2001). Role of left posterior superior temporal gyrus in phonological processing for speech perception and production. Cognitive Science.

Budde, K. S., Barron, D. S., \& Fox, P. T. (2014). Stuttering, induced fluency, and natural fluency: a hierarchical series of activation likelihood estimation meta-analyses. Brain and Language, 139, 99107. http://doi.org/10.1016/j.bandl.2014.10.002

Brocklehurst, P. H., Lickley, R. J., \& Corley, M. (2013). Revisiting Bloodstein's Anticipatory Struggle Hypothesis from a psycholinguistic perspective: A Variable Release Threshold hypothesis of stuttering. Journal of Communication Disorders, 46(3), 217-237. http://doi.org/10.1016/i.jcomdis.2013.04.002

Bernstein Ratner, N. (1997). Stuttering: a psycholinguistic perspective. In: Curlee R, Siegel GM, editors. Nature and treatment of stuttering: New directions. 2. Boston, MA: Allyn \& Bacon. pp. 99127.

Bernstein Ratner, N., \& Wijnen, F. (2007). The Vicious Cycle: Linguistic Encoding, Self- Monitoring and Stuttering. In Research, Treatment and Self-help in Fluency Disorders - New Horizons: Proceedings of the Fifth World Congress on Fluency Disorders (pp. 84-90). The International Fluency Association. ISBN-13 : 978-0955570018.

Bostan A.C., Dum R.P., Strick P.L. (2010). The basal ganglia communicate with the cerebellum. Proc Natl Acad Sci U S A. 2010 May 4;107(18):8452-6. doi: 10.1073/pnas.1000496107. PMID: 20404184; PMCID: PMC2889518. 
Bostan, A. C., \& Strick, P. L. (2018). The basal ganglia and the cerebellum: nodes in an integrated network. Nature reviews. Neuroscience, 19(6), 338-350. https://doi.org/10.1038/s41583-018-0002-7

Buhr, A. \& Zebrowski, P. (2009). Sentence position and syntactic complexity of stuttering in early childhood: A longitudinal study. Journal of Fluency Disorders 34, 155-172.

Cabrera, D., Sato, H., Martens, W. L., \& Lee, D. (2009). Binaural Measurement and Simulation of the Room Acoustical Response From a Person's Mouth to Their Ears. Acoustics Australia, 37.

Cacciola, A., Calamuneri, A., Milardi, D., Mormina, E., Chillemi, G., Marino, S., Naro, A., Rizzo, G., Anastasi, G., \& Quartarone, A. (2017). A Connectomic Analysis of the Human Basal Ganglia Network. Frontiers in neuroanatomy, 11, 85. https://doi.org/10.3389/fnana.2017.00085

Cai, S., Beal, D. S., Ghosh, S. S., Tiede, M. K., Guenther, F. H., \& Perkell, J. S. (2012). Weak responses to auditory feedback perturbation during articulation in persons who stutter: evidence for abnormal auditory-motor transformation. Plos One, 7(7), e41830. http://doi.org/10.1371/journal.pone.0041830

Calabresi, P., Picconi, B., Tozzi, A., Ghiglieri, V., \& Di Filippo, M. (2014). Direct and indirect pathways of basal ganglia: a critical reappraisal. Nature Publishing Group, 17(8), 1022-1030. http://doi.org/10.1038/nn.3743

Caligiore, D., Pezzulo, G., Baldassarre, G., Bostan, A. C., Strick, P. L., Doya, K., Helmich, R. C., Dirkx, M., Houk, J., Jörntell, H., Lago-Rodriguez, A., Galea, J. M., Miall, R. C., Popa, T., Kishore, A., Verschure, P. F., Zucca, R., \& Herreros, I. (2017). Consensus Paper: Towards a Systems-Level View of Cerebellar Function: the Interplay Between Cerebellum, Basal Ganglia, and Cortex. Cerebellum (London, England), 16(1), 203-229. https://doi.org/10.1007/s12311-016-0763-3

Campbell, P., Constantino, C. \& Simpson, S. (eds) (2019). Stammering Pride and Prejudice: Difference not Deficit. J \& R Press.

Chang, E. F., Niziolek, C. A., Knight, R. T., Nagarajan, S. S., \& Houde, J. F. (2013). Human cortical sensorimotor network underlying feedback control of vocal pitch. Proceedings of the National Academy of Sciences, 110(7), 2653-2658. http://doi.org/10.1073/pnas.1216827110

Chang S.-E., Guenther F. H. (2020). Involvement of the cortico-basal ganglia-thalamocortical loop in developmental stuttering. Front. Psychol. 10:3088. 10.3389/fpsyg.2019.03088

Cherry, C., Sayers, B. M. \& Marland, P.M. (1956). Experiments upon the total inhibition of stammering by external control, and some clinical results. Journal of Psychosomatic Research, 1, 233246. https://doi.org/10.1016/0022-3999(56)90001-0

Chordekar, S., Perez, R., Adelman, C., Sohmer, H., \& Kishon-Rabin, L. (2018). Does hearing in response to soft-tissue stimulation involve skull vibrations? A within-subject comparison between skull vibration magnitudes and hearing thresholds. Hearing Research, 364, 59-67. http://doi.org/10.1016/i.heares.2018.03.030

Ciocca, V. (2008). The auditory organization of complex sounds. Frontiers in Bioscience, 13(1), 148-169. http://doi.org/10.2741/2666

Civier, O., Bullock, D., Max, L., \& Guenther, F. H. (2013). Computational modeling of stuttering caused by impairments in a basal ganglia thalamo-cortical circuit involved in syllable selection and initiation. Brain and Language, 126(3), 263-278. http://doi.org/10.1016/j.bandl.2013.05.016

Civier, O., Tasko, S. M., \& Guenther, F. H. (2010). Overreliance on auditory feedback may lead to sound/syllable repetitions: simulations of stuttering and fluency-inducing conditions with a neural model of speech production. Journal of Fluency Disorders, 35(3), 246-279. http://doi.org/10.1016/j.jfludis.2010.05.002

Choo, A.L., Smith, S.A. \& Li, H. (2020). Associations between stuttering, comorbid conditions and executive function in children: a population-based study. BMC Psychol 31;8(1):113. doi: 10.1186/s40359-020-00481-7.

Cody, A. R., Wilson, W., \& Leah, J. (1996). Acoustically activated c-fos expression in auditory nuclei of the anaesthetised guinea pig. Brain Research, 728(1), 72-78.

Colebatch, J. G., Govender, S., \& Rosengren, S. M. (2013). Two distinct patterns of VEMP changes with age. Clinical Neurophysiology : Official Journal of the International Federation of Clinical Neurophysiology, 124(10), 2066-2068. http://doi.org/10.1016/i.clinph.2013.04.337 
Constantino, C. D., Eichorn, N., Buder, E. H., Beck, J. G., \& Manning, W. H. (2020). The Speaker's Experience of Stuttering: Measuring Spontaneity. Journal of Speech, Language, and Hearing Research, 63(4), 983-1001. http://doi.org/10.1044/2019 JSLHR-19-00068

Cooke, M., \& Ellis, D. P. W. (2001). The auditory organization of speech and other sources in listeners and computational models. Speech Communication, 35(3-4), 141-177. http://doi.org/10.1016/S01676393(00)00078-9

Craig, A., Hancock, K., Tran, Y., Craig, M., \& Peters, K. (2002). Epidemiology of stuttering in the community across the entire life span. Journal of Speech, Language, and Hearing Research, 45, 10971105.

Crivellaro Goncalves, I., Furquim de Andrade, C. R., \& Gentile Matas, C. (2015). Auditory Processing of Speech and Non-Speech Stimuli in Children who Stutter: Electrophysiological Evidences. Brain Disorders \& Therapy, 04(05), 1-5. http://doi.org/10.4172/2168-975X.1000199

Cullinan. W.L. and Springer, M.T. (1980) Voice initiation and termination times in stuttering and nonstuttering children., Journal of Speech and Hearing Research, 2, 344-60.

Curthoys, I. S. (2017). The new vestibular stimuli: sound and vibration-anatomical, physiological and clinical evidence. Experimental Brain Research, 235(4), 957-972. http://doi.org/10.1007/s00221-0174874-y

Curthoys, I. S., \& Grant, J. W. (2015). How does high-frequency sound or vibration activate vestibular receptors? Experimental Brain Research, 233(3), 691-699. http://doi.org/10.1007/s00221-014- 41926

Curthoys, I. S., Grant, J. W., Burgess, A. M., Pastras, C. J., Brown, D. J., \& Manzari, L. (2018). Otolithic Receptor Mechanisms for Vestibular- Evoked Myogenic Potentials: A Review. Frontiers in Neurology, 9, 366. http://doi.org/10.3389/fneur.2018.00366

Curthoys, I. S., Grant, J. W., Pastras, C. J., Brown, D. J., Burgess, A. M., Brichta, A. M., \& Lim, R. (2019). A review of mechanical and synaptic processes in otolith transduction of sound and vibration for clinical VEMP testing. Journal of Neurophysiology. http://doi.org/10.1152/jn.00031.2019

Curthoys, I. S., Kim, J., McPhedran, S. K., \& Camp, A. J. (2006). Bone conducted vibration selectively activates irregular primary otolithic vestibular neurons in the guinea pig. Experimental Brain Research, 175(2), 256-267. http://doi.org/10.1007/s00221-006-0544-1

DeLong, M.R. Primate models of movement disorders of basal ganglia origin. (1990).Trends Neurosci. 13, 281-285.

Denhardt (1890). Das Stottern: eine Psychose. Leipsig.

Drayna D, Kilshaw J, Kelly J. (1999). The sex ratio in familial persistent stuttering. Am. J. Hum. Genet.65:1473-75

Dunovan, K., Lynch, B., Molesworth, T., \& Verstynen, T. (2015). Competing basal ganglia pathways determine the difference between stopping and deciding not to go. eLife, 4 (September 2015), e08723. http://doi.org/10.7554/eLife.08723

Eisenson, J and Horowitz, E (1945) "The influence of propositionality on stuttering" Journal of Speech Disorders, 10, 193-197.

Ekdale E. G. (2013). Comparative Anatomy of the Bony Labyrinth (Inner Ear) of Placental Mammals. PloS one, 8(6), e66624. https://doi.org/10.1371/journal.pone.0066624

Eliades, S. J., \& Wang, X. (2017). Contributions of sensory tuning to auditory-vocal interactions in marmoset auditory cortex. Hearing Research, 348, 98-111.

http://doi.org/10.1016/j.heares.2017.03.001

Eliades, S. J., \& Tsunada, J. (2018). Auditory cortical activity drives feedback-dependent vocal control in marmosets. Nature Communications, 9(1), 2540-13. http://doi.org/10.1038/s41467-018-04961-8

Ellis, J. (2020). The Clearing: Music, dysfluency, blackness and time. Journal of Interdisciplinary Voice Studies, Volume 5, number 2, 215-233.

Elsherif M.M., Wheeldon L.R., Frisson S. (2021). Do dyslexia and stuttering share a processing deficit? J Fluency Disord. 67:105827. doi: 10.1016/j.jfludis.2020.105827.

Etchell, A. C., Civier, O., Ballard, K. J., \& Sowman, P. F. (2017). A systematic literature review of neuroimaging research on developmental stuttering between 1995 and 2016. Journal of Fluency Disorders. http://doi.org/10.1016/j.jfludis.2017.03.007 
Evans J. St. (2007). "Dual-processing accounts of reasoning, judgment, and social cognition". Annual Review of Psychology. 59: 268-269. doi:10.1146/annurev.psych.59.103006.093629. PMID 18154502.

Fairbanks G. (1954) Systematic Research In Experimental Phonetics: 1. A Theory Of The Speech Mechanism As A Servosystem. Journal of Speech and Hearing Disorders; 19(2):133-139. https://doi. org/10.1044/jshd.1902.133 PMID: 13212816

Fenoy, A. J., Severson, M. A., Volkov, I. O., Brugge, J. F., \& Howard, M. A. (2006). Hearing suppression induced by electrical stimulation of human auditory cortex. Brain Research, 1118(1), 75-83. http://doi.org/10.1016/j.brainres.2006.08.013

Fernyhough, C., \& Russell, J. (1997). Distinguishing Ones Own Voice from Those of Others A Function for Private Speech. International Journal of Behavioral ....

Florentine M., Popper A., Fay R. (eds) Loudness. Springer Handbook of Auditory Research, vol 37. Springer, New York, NY. https://doi.org/10.1007/978-1-4419-6712-1_5

Fodor, Jerry A., (1987) "Meaning and the world order" from Fodor, Jerry, A., Psychosemantics: the problem of meaning in the philosophy of mind pp.97-127, Cambridge, Massachusetts: The MIT Press

Ford, J. M. \& Mathalon, D. H. (2004). Electrophysiological evidence of corollary discharge dysfunction in schizophrenia during talking and thinking. Journal of Psychiatric Research, 38(1), 37-46. http://doi.org/10.1016/s0022-3956(03)00095-5

Foundas, A. L., Mock, J. R., Corey, D. M., Golob, E. J., \& Conture, E. G. (2013). The SpeechEasy device in stuttering and nonstuttering adults: fluency effects while speaking and reading. Brain and Language, 126(2), 141-150. http://doi.org/10.1016/i.bandl.2013.04.004

Frigerio-Domingues, C., \& Drayna, D. (2017). Genetic contributions to stuttering: the current evidence. Molecular Genetics \& Genomic Medicine, 5(2), 95-102. http://doi.org/10.1002/mgg3.276

Fu, C. H. Y., Vythelingum, G. N., Brammer, M. J., Williams, S. C. R., Amaro, E., Andrew, C. M., ... McGuire, P. K. (2006). An fMRI study of verbal self-monitoring: Neural correlates of auditory verbal feedback. Cerebral Cortex, 16(7), 969-977. https://doi.org/10.1093/cercor/bhj039

Garcia-Barrera, M. A., \& Davidow, J. H. (2015). Anticipation in stuttering: A theoretical model of the nature of stutter prediction. Journal of Fluency Disorders, 44, 1-15. http://doi.org/10.1016/j.jfludis.2015.03.002

Gattie, M.C.D., Howell, P., Kluk, K., \& Lieven, E. (2019, June 30). Vestibular Evoked Myogenic Potentials in Persistent Developmental Stuttering. Retrieved from osf.io/9mukg

Gattie, M.C.D., Lieven, E. \& Kluk, K. (submitted, 2020) Weak vestibular response in persistent developmental stuttering

Galantucci B., Fowler C.A., Turvey M.T. (2006). The motor theory of speech perception reviewed. Psychonomic Bulletin \& Review;13(3):361-377.

Gallagher, S. \& Zahavi, D. (2021). "Phenomenological Approaches to Self-Consciousness", The Stanford Encyclopedia of Philosophy (Spring 2021 Edition), Edward N. Zalta (ed.), URL = <https://plato.stanford.edu/archives/spr2021/entries/self-consciousness-phenomenological/>.

Goldberg, J.M. (ed) (2012), The vestibular system: a sixth sense. (2012). Oxford University Press Inc Golding, N. L., \& Oertel, D. (2012). Synaptic integration in dendrites: exceptional need for speed. The Journal of Physiology, 590(22), 5563-5569. http://doi.org/10.1113/jphysiol.2012.229328

Gould, E. \& Sheehan, J (1967). "Effect of silence on stuttering" Journal of Abnormal Psychology, 72, 5, 441-445.

Govender, S., Todd, N. P. M., \& Colebatch, J. G. (2020). Mapping the vestibular cerebellar evoked potential (VSCEP) following air- and bone-conducted vestibular stimulation. Experimental Brain Research, 238(3), 601-620. http://doi.org/10.1007/s00221-020-05733-x

Grant, W., \& Curthoys, I. (2017). Otoliths - Accelerometer and seismometer; Implications in Vestibular Evoked Myogenic Potential (VEMP). Hearing Research, 353, 26-35. http://doi.org/10.1016/j.heares.2017.07.012 
Greenlee, J. D. W., Jackson, A. W., Chen, F., Larson, C. R., Oya, H., Kawasaki, H., et al. (2011). Human Auditory Cortical Activation during Self-Vocalization. Plos One, 6(3), e14744.

http://doi.org/10.1371/journal.pone.0014744

Gregory, H.H. (ed.) (1979). Controversies about Stuttering Therapy. Baltimore: University Park Press. Grice, P. (1957). 'Meaning', The Philosophical Review, 66: 377-88.

Grice, P. (1989). Studies in the Way of Words Cambridge MA: Harvard University Press.

Guenther, F. H., Ghosh, S. S., \& Tourville, J. A. (2006). Neural modeling and imaging of the cortical interactions underlying syllable production. Brain and Language, 96, 280-301.

Haas, H. (1951). "Uber den Einfluss eines Einfachechos auf die Horsamkeit von Sprache," Acustica, 1, 4958.

Haber S. N. (2014). The place of dopamine in the cortico-basal ganglia circuit. Neuroscience, 282, 248257. https://doi.org/10.1016/i.neuroscience.2014.10.008

Hadamard, J. (1902). Sur les problèmes aux dérivées partielles et leur signification physique. Princeton University Bulletin. pp. 49-52.

Hadamard, J. (1923). Lectures on Cauchy's Problem in Linear Partial Differential Equations. Yale University Press, New Haven CT.

Han, T.-U., Root, J., Reyes, L. D., Huchinson, E. B., Hoffmann, Du, J., Lee, W. S., et al. (2019). Human GNPTAB stuttering mutations engineered into mice cause vocalization deficits and astrocyte pathology in the corpus callosum. Proceedings of the National Academy of Sciences of the United States of America, 116(35), 17515-17524. http://doi.org/10.1073/pnas.1901480116

Hannley, M., \& Dorman, M. F. (1982). Some observations on auditory function and stuttering. Journal of Fluency Disorders, 7(1), 93-108. http://doi.org/10.1016/S0094-730X(82)80003-X

Helmholtz, H. (1886). Handbuch der Physiologischen Optik. Leipzig: Voss.

Herder, C., Howard, C., Nye, C., Vanryckeghem, M., (2006). Effectiveness of behavioural stuttering treatment: a systematic review and meta-analysis. Contemporary Issues in Communication Science and Disorders, 33, 61-73.

Hickok, G., \& Poeppel, D. (2007). The cortical organization of speech processing. Nature Reviews Neuroscience, 8(5), 393-402. http://doi.org/doi:10.1038/nrn2113

Hickok, G. (2017). A cortical circuit for voluntary laryngeal control: Implications for the evolution language. Psychon Bull Rev 24, 56-63. https://doi.org/10.3758/s13423-016-1100-z

Hickok, G., Houde, J., \& Rong, F. (2011). Sensorimotor integration in speech processing: computational basis and neural organization. Neuron, 69(3), 407-422. http://doi.org/10.1016/i.neuron.2011.01.019

Hirano, S., Kojima, H., Naito, Y., Honjo, I., Kamoto, Y., Okazawa, H., . . Konishi, J. (1997). Cortical processing mechanism for vocalization with auditory verbal feedback. NeuroReport, 8(9-10), 23792382.

von Holst, E., and Mittelstädt, H. (1950). Das reafferenzprinzip. Naturwissenschaften 37, 464-476. doi: $10.1007 /$ bf00622503

Hoshi E., Tremblay L., Féger J., Carras P.L., Strick P.L. (2005). The cerebellum communicates with the basal ganglia. Nat Neurosci;8(11):1491-1493. doi: 10.1038/nn1544.

Hotehama, T., \& Nakagawa, S. (2012). Propagation Velocity of Bone-Conducted Ultrasound in the Human Head. Japanese Journal of Applied Physics, 51(7S), 07GF21. http://doi.org/10.1143/JJAP.51.07GF21

Houde, J. F., \& Nagarajan, S. S. (2016). Speech motor control from a modern control theory perspective. Neurobiology of Language. http://doi.org/10.1016/B978-0-12-407794-2.00019-5

Houde, J. F., \& Chang, E. F. (2015). The cortical computations underlying feedback control in vocal production. Current Opinion in Neurobiology, 33, 174-181. http://doi.org/10.1016/j.conb.2015.04.006

Howell, P., El-Yaniv, N., \& Powell, D. J. (1987). Factors affecting fluency in stutterers when speaking under altered auditory feedback. In H. Peters \& W. Hulstijn (Eds.), (pp. 361-369). Speech Motor Dynamics in Stuttering.

Howell, P. (2004). Effects of delayed auditory feedback and frequency-shifted feedback on speech control and some potentials for future development of prosthetic aids for stammering. Stammering Research : an on-Line Journal Published by the British Stammering Association, 1(1), 31-46.

Howell, P., Marchbanks, R. J., \& El-Yann, N. (1986). Middle ear muscle activity during vocalization in normal speakers and stutterers. Acta Oto-Laryngologica, 102(5-6), 396-402. http://doi.org/10.3109/00016488609119423 
Howell, P., Powell, D. J., \& Khan, I. (1983). Amplitude contour of the delayed signal and interference in delayed auditory feedback tasks. Journal of Experimental Psychology, 1-13.

Huettig, F., \& Hartsuiker, R. J. (2010). Listening to yourself is like listening to others: External, but not internal, verbal self-monitoring is based on speech perception. Language and Cognitive Processes, 25(3), 347-374. http://doi.org/10.1080/01690960903046926

Irvine D.R.F. (1992) Physiology of the Auditory Brainstem. In: Popper A.N., Fay R.R. (eds) The Mammalian Auditory Pathway: Neurophysiology. Springer Handbook of Auditory Research, vol 2. Springer, New York, NY

Isaacs, D. (2020). 'I Don't Have Time For This': Stuttering and the Politics of University Time. Scandinavian Journal of Disability Research, 22(1), 58-67. DOI: http://doi.org/10.16993/sjdr.601

Iverach, L., Rapee, R. M., Wong, Q. J. J., \& Lowe, R. (2017). Maintenance of Social Anxiety in Stuttering: A Cognitive-Behavioral Model. American Journal of Speech-Language Pathology, 26(2), 540-17. http://doi.org/10.1044/2016 AJSLP-16-0033

Jackson, E., Yaruss, J. S., Quesal, R. W., Terranova, V., \& Whalen, D. (2015). Responses of adults who stutter to the anticipation of stuttering. Journal of Fluency Disorders, 45, 38-51.

Jones, D. K., Knösche, T. R., \& Turner, R. (2013). White matter integrity, fiber count, and other fallacies: The do's and don'ts of diffusion MRI. Neurolmage, 73, 239-254. doi:10.1016/j. neuroimage.2012.06.081

Jürgens, U. (2002). Neural pathways underlying vocal control. Neuroscience \& Biobehavioral Reviews, 26(2), 235-258.

Johnson, M., Baxter, S., Blank, L., Cantrell, A., Brumfitt, S., Enderby, P., \& Goyder, E. (2015). The state of the art in non-pharmacological interventions for developmental stuttering. Part 2: qualitative evidence synthesis of views and experiences. International Journal of Language \& Communication Disorders, 51(1), 3-17. http://doi.org/10.1111/1460-6984.12182

Johnson, W. (1961). Stuttering and what you can do about it. Danville, IL: The Interstate Printers \& Publishers, Inc

Jones, L. A., Hills, P. J., Dick, K. M., Jones, S. P., \& Bright, P. (2016). Cognitive mechanisms associated with auditory sensory gating. Brain and cognition, 102, 33-45. https://doi.org/10.1016/j.bandc.2015.12.005

Kaga, K. (2016). Auditory nerve disease and auditory neuropathy spectrum disorders. Auris, Nasus, Larynx, 43(1), 10-20. http://doi.org/10.1016/j.anl.2015.06.008

Kahneman, D. (2011). Thinking, fast and slow (1st ed.). New York: Farrar, Straus and Giroux. ISBN 9780374275631.

Kalinowski, J., Armson, J., Roland-Mieszkowski, M., Stuart, A. and Gracco, V. L. (1993). Effects of alterations in auditory feedback and speech rate on stuttering frequency. Language and Speech, 36, $1-16$.

Kaplan, J. T., Aziz-Zadeh, L., Uddin, L. Q., \& lacoboni, M. (2008). The self across the senses: an fMRI study of self-face and self-voice recognition. Social Cognitive and Affective Neuroscience, 3(3), 218-223. http://doi.org/10.1093/scan/nsn014

Karniol, R. (1995) Stuttering, language, and cognition: A review and a model of stuttering as suprasegmental sentence plan alignment (SPA). Psychological Bulletin, 117, 104-124.

Kato T, Shiraishi K, Eura Y, Shibata K, Sakata T, Morizono T, Soda T. (1998) A 'neural' response with 3ms latency evoked by loud sound in profoundly deaf patients. Audiol Neurootol;3:253-64.

Kern (1932) Der Einflusz des Hiirens auf das Stottern. Arch. Psychiat. 97, 429449.

Kobayashi, H., \& Hayasaka, K. (2003). Manual Diadochokinetic Movements in Children with Stuttering and Phonologicial Disorders. Japanese Journal of Special Education, 40, 649-662.

Kolarik, A. J., Cirstea, S., Pardhan, S., \& Moore, B. C. J. (2014). A summary of research investigating echolocation abilities of blind and sighted humans. Hearing Research, 310, 60-68. http://doi.org/10.1016/i.heares.2014.01.010

Kraft, S. J., \& Yairi, E. (2012). Genetic Bases of Stuttering: The State of the Art, 2011. Folia Phoniatrica Et Logopaedica, 64(1), 33-46. http://doi.org/10.1159/000331073 
Kramer, M. B., Green, D., \& Guitar, B. (1987). A comparison of stutterers and nonstutterers on masking level differences and synthetic sentence identification tasks. Journal of Communication Disorders, 20(5), 379-390.

Kröger, B. J., Crawford, E., Bekolay, T., \& Eliasmith, C. (2016). Modeling Interactions between Speech Production and Perception: Speech Error Detection at Semantic and Phonological Levels and the Inner Speech Loop. Frontiers in Computational Neuroscience, 10, 51. http://doi.org/10.3389/fncom.2016.00051

Lakatos, I.M. (1970) "Falsification and the Methodology of Scientific Research Programmes", in Lakatos \& Musgrave (eds) Criticism and the Growth of Knowledge, Cambridge: Cambridge University Press.

Langová, J \& Sváb, L (1973) "Reduction of stuttering under experimental social isolation: The role of adaptation effect" Folia Phoniatrica, 25, 17-22.

Langová, J., Morávek, M., Široký \& Sváb, L. (1975) "Effect of speaking on evoked vestibular nystagmus in stutterers" Folia Phoniatrica, 27(4), 287-291.

Laukli, E., \& Burkard, R. (2015). Calibration/Standardization of Short-Duration Stimuli. Seminars in Hearing, 36(1), 3-10. http://doi.org/10.1055/s-0034-1396923

Levelt, W.J. (1989) Speaking: From intention to articulation Cambridge, MA: MIT Press.

Levelt, W.J., Roelofs, A., \& Meyer, A. S. (1999). A theory of lexical access in speech production. The Behavioral and Brain Sciences, 22(1), 1-38- discussion 38-75. http://doi.org/10.1017/s0140525x99001776

Liebetrau, R. M., \& Daly, D. A. (1981). Auditory processing and perceptual abilities of "organic" and 'functional' stutterers. Journal of Fluency Disorders.

Liberman, A. M., \& Mattingly, I. G. (1985). The motor theory of speech perception revised. Cognitive and Behavioral Neurology, 21(1), 1-36.

Lind, A., Hall, L., Breidegard, B., Balkenius, C., \& Johansson, P. (2014). Auditory feedback of one's own voice is used for high-level semantic monitoring: the 'self-comprehension' hypothesis. Frontiers in Human Neuroscience, 8, 166. http://doi.org/10.3389/fnhum.2014.00166

Liotti, M., Ingham, J. C., Takai, O., Paskos, D. K., Perez, R., \& Ingham, R. J. (2010). Spatiotemporal dynamics of speech sound perception in chronic developmental stuttering. Brain and Language, 115(2), 141-147. http://doi.org/10.1016/j.bandl.2010.07.007

Lipton, P. (2004). Inference to the Best Explanation, (2nd ed.), London: Routledge.

Ludlow, C. L., \& Loucks, T. (2003). Stuttering: a dynamic motor control disorder. Journal of Fluency Disorders, 28(4), 273-95- quiz 295. http://doi.org/10.1016/j.jfludis.2003.07.001

Lupyan, G., \& Swingley, D. (2012). Self-directed speech affects visual search performance. Quarterly Journal of Experimental Psychology (2006), 65(6), 1068-1085. http://doi.org/10.1080/17470218.2011.647039

MacCulloch, M. J., \& Eaton, R. (1971). A note on reduced auditory pain threshold in 44 stuttering children. The British Journal of Disorders of Communication, 6(2), 148-153. http://doi.org/10.3109/13682827109011541

MacKay D. G. (1969). Effects of ambiguity on stuttering: towards a theory of speech production at the semantic level. Kybernetik, 5(5), 195-208. https://doi.org/10.1007/BF00288943

Maffei, C., Sarubbo, S., \& Jovicich, J. (2019). A Missing Connection: A Review of the Macrostructural Anatomy and Tractography of the Acoustic Radiation. Frontiers in Neuroanatomy, 13. http://doi.org/10.3389/fnana.2019.00027

Manley, G. A., Gummer, A., Popper, A.N. \& Fay, R.R. (eds) (2017). Understanding the Cochlea. Springer Science \& Business Media.

Maraist, J. A. and Hutton, C. (1957) Effects of auditory masking upon the speech of stutterers. J. Speech Dis. 22, 385-389.

Mason S, Garnham C \& Hudson B. (1996) Electric response audiometry in young children before cochlear implantation: a short latency component. Ear Hear. 17:537-43.

Matuschek, H., Kliegl, R., Vasishth, S., Baayen, H., \& Bates, D. (2017). Balancing Type I error and power in linear mixed models. Journal of Memory and Language, 94, 305-315.

http://doi.org/10.1016/i.jml.2017.01.001

Maurer, D., \& Landis, T. (1990). Role of Bone Conduction in the Self-Perception of Speech. Folia Phoniatrica Et Logopaedica, 42(5), 226-229. http://doi.org/10.1159/000266070 
Maguire, G. A., Nguyen, D. L., Simonson, K. C., \& Kurz, T. L. (2020). The Pharmacologic Treatment of Stuttering and Its Neuropharmacologic Basis. Frontiers in Neuroscience, 14, 158. http://doi.org/10.3389/fnins.2020.00158

Månsson H. (2000) Identification of stuttering in pre- school children: a multifactorial, longitudinal study in development. J Fluency Disord;25(3):241

Martin, D. (2016). Stuttering from the Anus. Canadian Journal of Disability Studies, 5(3), 114-134. https://doi.org/10.15353/cjds.v5i3.299

Mariën, P., \& Manto, M. (2015).The linguistic cerebellum. Academic Press.

Matthews, N., Todd, J., Mannion, D. J., Finnigan, S., Catts, S., \& Michie, P. T. (2013). Impaired processing of binaural temporal cues to auditory scene analysis in schizophrenia. Schizophrenia Research, 146(13), 344-348. http://doi.org/10.1016/j.schres.2013.02.013

Max, L., Guenther, F. H., Gracco, V. L., Ghosh, S. S., \& Wallace, M. E. (2004). Unstable or insufficiently activated internal models and feedback-biased motor control as sources of dysfluency: A theoretical model of stuttering. Contemporary Issues in Communication Science and Disorders, 31, 105-122.

Max, L. (2004). Stuttering and internal models for sensorimotor control: A theoretical perspective to generate testable hypotheses. In B. Maassen, R. Kent, H. F. M. Peters, P. van Lieshout, \& W. Hulstijn (Eds.), Speech motor control in normal and disordered speech (pp. 357-387). Oxford, UK: Oxford University Press.

Max, L., \& Baldwin, C. J. (2010). The role of motor learning in stuttering adaptation: repeated versus novel utterances in a practice-retention paradigm. Journal of Fluency Disorders, 35(1), 33-43. http://doi.org/10.1016/i.jfludis.2009.12.003

McLachlan, N. M., Phillips, D. S., Rossell, S. L., \& Wilson, S. J. (2013). Auditory processing and hallucinations in schizophrenia. Schizophrenia Research, 150(2-3), 380-385. http://doi.org/10.1016/j.schres.2013.08.039

McKnight, R. C., \& Cullinan, W. L. (1987). Subgroups of stuttering children: Speech and voice reaction times, segmental durations, and naming latencies. Journal of Fluency Disorders, 12(3), 217-233. doi:10.1016/0094-730X(87)90028-3

McNerney, K. M., \& Burkard, R. F. (2011). The vestibular evoked myogenic potential (VEMP): air- versus bone-conducted stimuli. Ear and Hearing, 32(6), e6-e15.

http://doi.org/10.1097/AUD.0b013e3182280299

Meekings, S., Boebinger, D., Evans, S., Lima, C. F., Chen, S., Ostarek, M., \& Scott, S. K. (2015). Do We Know What We're Saying? The Roles of Attention and Sensory Information During Speech Production. Psychological Science, 26(12), 1975-1977. http://doi.org/10.1177/0956797614563766

Meibauer, J. \& Steinbach, M. (2011). Experimental Pragmatics/semantics. Amsterdam: John Benjamins Pub. Co. ISBN 9789027255587

Metzger, F. L., Auer, T., Helms, G., Paulus, W., Frahm, J., Sommer, M., \& Neef, N. E. (2017). Shifted dynamic interactions between subcortical nuclei and inferior frontal gyri during response preparation in persistent developmental stuttering. Brain Structure \& Function, 223(1), 165-182. http://doi.org/10.1007/s00429-017-1476-1

Milardi, D., Quartarone, A., Bramanti, A., Anastasi, G., Bertino, S., Basile, G. A., Buonasera, P., Pilone, G., Celeste, G., Rizzo, G., Bruschetta, D., \& Cacciola, A. (2019). The Cortico-Basal Ganglia-Cerebellar Network: Past, Present and Future Perspectives. Frontiers in systems neuroscience, 13, 61. https://doi.org/10.3389/fnsys.2019.00061

Miller N.E. (1944) Experimental Studies of Conflict. In Hunt, J. McV (ed) "Personality and the Behavior Disorders". New York: Ronald Press.

Mink, J. W. (1996). The basal ganglia: Focused selection and inhibition of competing motor programs. Progress in Neurobiology, 50, 381-425.

Mink, J. W. (2018). Basal ganglia mechanisms in action selection, plasticity, and dystonia. European Journal of Paediatric Neurology : EJPN : Official Journal of the European Paediatric Neurology Society, 22(2), 225-229. http://doi.org/10.1016/i.ejpn.2018.01.005

Mozaffarilegha, M., Namazi, H., Tahaei, A. A., \& Jafari, S. (2019). Complexity-Based Analysis of the Difference Between Normal Subjects and Subjects with Stuttering in Speech Evoked Auditory 
Brainstem Response. Journal of Medical and Biological Engineering, 39(4), 490-497. http://doi.org/10.1007/s40846-018-0430-x

Murofushi, T., Iwasaki, S., Takai, Y., \& Takegoshi, H. (2005). Sound-evoked neurogenic responses with short latency of vestibular origin. Clinical Neurophysiology, 116(2), 401-405. http://doi.org/10.1016/j.clinph.2004.09.005

Musicant A. D. \& Butler R. A. (1984). The influence of pinnae-based spectral cues on sound localization. The Journal of the Acoustical Society of America, 75(4): 1195-1200

Mysak, E.D. (1969). Speech Pathology and Feedback Theory. Charles C Thomas, Illinois.

Nakagawa, S., Johnson, P.C.D. \& Schielzeth, H. (2017). The Coefficient of Determination R2 and IntraClass Correlation Coefficient from Generalized Linear Mixed-Effects Models Revisited and Expanded. Journal of the Royal Society Interface 14 (134): 20170213. https://doi.org/10.1098/rsif.2017.0213.

Neef, N. E., Anwander, A., \& Friederici, A. D. (2015). The Neurobiological Grounding of Persistent Stuttering: from Structure to Function. Current Neurology and Neuroscience Reports, 15(9), 63. http://doi.org/10.1007/s11910-015-0579-4

Neelly, J. M. (1961) A study of the speech behaviour of stutterers and nonstutterers under normal and delayed auditory feedback. / . speech hear. Disord. monogr. Suppl, No. 7.

Newlands, S. D., Vrabec, J. T., Purcell, I. M., Stewart, C. M., Zimmerman, B. E., \& Perachio, A. A. (2003). Central projections of the saccular and utricular nerves in macaques. The Journal of Comparative Neurology, 466(1), 31-47. http://doi.org/10.1002/cne.10876

Nong, D. X., Ura, M., Owa, T., \& Noda, Y. (2000). An acoustically evoked short latency negative response in profound hearing loss patients. Acta Oto-Laryngologica, 120(8), 960-966. http://doi.org/10.1080/00016480050218708

Nong, D. X., Ura, M., Kyuna, A., Owa, T., \& Noda, Y. (2002). Saccular origin of acoustically evoked short latency negative response. Otology \& Neurotology, 23(6), 953-957. http://doi.org/10.1097/00129492-200211000-00024

Norris, D., McQueen, J. M., \& Cutler. (2000). Merging information in speech recognition: Feedback is never necessary. The Behavioral and Brain Sciences, 23(3), 299-325. http://doi.org/10.1017/S0140525X00003241

Noveck, I.A., and Sperber, D. (2004). Experimental Pragmatics. Basingstoke, Hampshire: Palgrave Macmillan. ISBN 9781403903501

Noveck, I.A. (2018). Experimental Pragmatics: The Making of a Cognitive Science. Cambridge: CUP. ISBN 9781107084902

Nozari, N., Dell, G. S., \& Schwartz, M. F. (2011). Is comprehension necessary for error detection? A conflict-based account of monitoring in speech production. Cognitive Psychology, 63(1), 1-33. http://doi.org/10.1016/j.cogpsych.2011.05.001

Ntourou, K. , Conture, E. G. , \& Lipsey, M. W. (2011). Language abilities of children who stutter: A metaanalytical review. American Journal of Speech-Language Pathology, 20(3), 163-179. https://doi.org/10.1044/1058-0360(2011/09-0102)

Nittrouer, S., \& Cheney, C. (1984). Operant techniques used in stuttering therapy: A review. Journal of Fluency Disorders, 9(3), 169-190. http://doi.org/10.1016/0094-730X(84)90011-1

Oliver, D.L., Cant, N.B., Fay, R.R. \& Popper, A.N. (eds) (2018) Vertebrate Sound Production and Acoustic Communication. Springer Handbook of Auditory Research, vol 65. Springer, New York, NY

Ofoe L.C., Anderson J.D., Ntourou K. (2018).Short-term memory, inhibition, and attention in developmental stuttering: a meta-analysis. J Speech Lang Hear Res;61(7):1626-1648. doi: 10.1044/2018_JSLHR-S-17-0372.

Ozdemir, R., Roelofs, A., \& Levelt, W. J. M. (2007). Perceptual uniqueness point effects in monitoring internal speech. Cognitive and Behavioral Neurology, 105(2), 457-465. http://doi.org/10.1016/j.cognition.2006.10.006

Papathanasiou E, Zamba-Papanicolaou E, Pantziaris M, Kyriakides T, Papacostas S, Myrianthopoulou P, et al. (2003) Click evoked neurogenic vestibular potentials (NVESTEPs): a method of assessing the function of the vestibular system. Electromyogr Clin Neurophysiol. 43:399-408. 
Papathanasiou ES, Theocharidou EK, Papacostas SS. (2006) Parallel auditory vestibular evoked neurogenic and myogenic potential results in a case of peripheral vestibular dysfunction, showing that the former originates from the vestibular system. Electromyogr Clin Neurophysiol. 46:105-11.

Papathanasiou ES, Zamba-Papanicolaou E, Pantziaris M, Kleopas K, Kyriakides T, Papacostas S, et al. (2004) Neurogenic vestibular evoked potentials using a tone pip auditory stimulus. Electromyogr Clin Neurophysiol. 44:167-73.

Parrell, B., Ramanarayanan, V., Nagarajan, S., \& Houde, J. (2019). The FACTS model of speech motor control: Fusing state estimation and task-based control. PLoS Computational Biology, 15(9), e1007321. http://doi.org/10.1371/journal.pcbi.1007321

Pelzer, E. A., Melzer, C., Timmermann, L., von Cramon, D. Y., \& Tittgemeyer, M. (2017). Basal ganglia and cerebellar interconnectivity within the human thalamus. Brain structure \& function, 222(1), 381-392. https://doi.org/10.1007/s00429-016-1223-z

Pidoux, L., Le Blanc, P., Levenes, C., \& Leblois, A. (2018). A subcortical circuit linking the cerebellum to the basal ganglia engaged in vocal learning. eLife, 7, e32167. https://doi.org/10.7554/eLife.32167

Pierre, J. S. (2015). Distending Straight-Masculine Time: A Phenomenology of the Disabled Speaking Body. Hypatia, 30(1), 49-65. http://doi.org/10.1111/hypa.12128

Poggio, T., \& Koch, C. (1985). Ill-posed problems in early vision: From computational theory to analogue networks. Proceedings of the Royal Society of London - Biological Sciences, 226(1244), 303-323. http://doi.org/10.1098/rspb.1985.0097

Poeppel, D., Idsardi, W. J., \& van Wassenhove, V. (2008). Speech Perception at the Interface of Neurobiology and Linguistics. Philosophical Transactions: Biological Sciences, 363(1493), 1071-1086.

Pörschmann, C. (2000). Influences of bone conduction and air conduction on the sound of one's own voice. Acta Acustica United with Acustica, 86(6), 1038-1045.

Postma, A. (2000). Detection of errors during speech production: A review of speech monitoring models. Cognitive and Behavioral Neurology, 77(2), 97-132. http://doi.org/10.1016/S0010-0277(00)00090-1

Rayleigh (J.W. Strutt, 3rd Baron Rayleigh) (1907) On our perception of sound direction. The London, Edinburgh, and Dublin Philosophical Magazine and Journal of Science, 13(74) XII: 214-232.

Reinfeldt, S., Östli, P., Håkansson, B., \& Stenfelt, S. (2010). Hearing one's own voice during phoneme vocalization-Transmission by air and bone conduction. The Journal of the Acoustical Society of America, 128(2), 751-762. http://doi.org/10.1121/1.3458855

Reynolds, J. N., Hyland, B. I., \& Wickens, J. R. (2001). A cellular mechanism of reward-related learning. Nature, 413, 67-70.

Rescorla, Michael (2019) "Convention", The Stanford Encyclopedia of Philosophy (Summer 2019 Edition), Edward N. Zalta (ed.), https://plato.stanford.edu/archives/sum2019/entries/convention/.

Richels C, Buhr A, Conture E, Ntourou K. (2010) Utterance complexity and stuttering on function words in preschool-age children who stutter. Journal of Fluency Disorders;35:314-331.

Rosa, C., Lassonde, M., Pinard, C., Keenan, J. P., \& Belin, P. (2008). Investigations of hemispheric specialization of self-voice recognition. Brain and Cognition, 68(2), 204-214. http://doi.org/10.1016/j.bandc.2008.04.007

Rosenfield D.B., Jerger J. (1984). Stuttering and auditory function. In: Curlee RF, Perkins WH, editors. Nature and treatment of stuttering: New directions. San Diego: College-Hill Press. pp. 73-87.

Rosengren, S. M., \& Colebatch, J. G. (2018). The Contributions of Vestibular Evoked Myogenic Potentials and Acoustic Vestibular Stimulation to Our Understanding of the Vestibular System. Frontiers in Neurology, 9, 481. http://doi.org/10.3389/fneur.2018.00481

Rousey, C. L., Goetzinger, C. P., \& Dirks, D. (1959). Sound localization ability of normal, stuttering, neurotic, and hemiplegic subjects. A.M.a. Archives of General Psychiatry, 1, 640-645.

Ryugo, D.K., Fay, R.R. \& Popper, A.N. (eds) (2011) Auditory and Vestibular Efferents. Springer Handbook of Auditory Research, vol 38. Springer, New York, NY

Sato, Y., Mori, K., Koizumi, T., Minagawa-Kawai, Y., Tanaka, A., Ozawa, E., et al. (2011). Functional lateralization of speech processing in adults and children who stutter. Frontiers in Psychology, 2, 70. http://doi.org/10.3389/fpsyg.2011.00070 
Schlindwein, P., Mueller, M., Bauermann, T., Brandt, T., Stoeter, P., \& Dieterich, M. (2008). Cortical representation of saccular vestibular stimulation: VEMPs in fMRI. Neurolmage, 39(1), 19-31. http://doi.org/10.1016/j.neuroimage.2007.08.016

Schultz, W. (2016). Dopamine reward prediction-error signalling: a two-component response. Nat Rev Neurosci. 2016 March ; 17(3): 183-195. doi:10.1038/nrn.2015.26.

Seery C.H., Watkins R.V., Mangelsdorf S.C., Shigeto A. (2007). Subtyping stuttering II: contributions from language and temperament. J Fluency Disord.;32(3):197-217. 10.1016/j.jfludis.2007.07.001 .

Shahed, J., \& Jankovic, J. (2001). Re-emergence of childhood stammering in Parkinson's disease: A hypothesis. Movement Disorders, 16, 114-118.

Shane, M. L. S. (1955) Effect on stuttering of alteration in auditory feedback. In Stuttering in children and adults. University of Minnesota Press, Minneapolis.

Sheehan, J.G. (1953) "Theory and treatment of stuttering as an approach-avoidance conflict", Journal of Psychology, 36, 27-49.

Sheehan, J.G., (1958) Conflict theory of stuttering. In Eisenson, J. (ed.), Stuttering: A Symposium. New York: Harper and Row.

Sheehan, J.G. (1970). Stuttering: Research and therapy. New York: Harper \& Row.

Sheehan, J.G. (1975). Conflict theory and avoidance reduction therapy. In J. Eisenson (Ed.), Stuttering: A second symposium (pp. 97-198). New York: Harper \& Row.

Sheehan, J., Hadley, R. \& Gould, E., (1967). "Impact of authority on stuttering" Journal of Abnormal Psychology, 72, 290-293.

Shuster, L. I., \& Durrant, J. D. (2003). Toward a better understanding of the perception of self-produced speech. Journal of Communication Disorders.

Singer, C. M., Hessling, A., Kelly, E. M., Singer, L., \& Jones, R. M. (2020). Clinical Characteristics Associated With Stuttering Persistence: A Meta-Analysis. Journal of Speech, Language, and Hearing Research, 63(9), 2995-3018. http://doi.org/10.1044/2020 JSLHR-20-00096

Skipper, J.I. \& Lamettie, D.R. (2021) Speech Perception under the Tent: A Domain-general Predictive Role for the Cerebellum. Journal of Cognitive Neuroscience 1-18. https://doi.org/10.1162/jocn_a_01729

Smith A., \& Kelly E. (1997). Stuttering: A dynamic, multifactorial model. In Curlee R. \& Siegel G. (Eds.), Nature and treatment of stuttering: New directions (pp. 204-217). Boston, MA: Allyn \& Bacon.

Smith, A., \& Weber, C. (2017). How Stuttering Develops: The Multifactorial Dynamic Pathways Theory. Journal of speech, language, and hearing research : JSLHR, 60(9), 2483-2505. https://doi.org/10.1044/2017 JSLHR-S-16-0343

Smith, J., "Self-Consciousness" (2020). The Stanford Encyclopedia of Philosophy (Summer 2020 Edition), Edward N. Zalta (ed.), URL = <https://plato.stanford.edu/archives/sum2020/entries/selfconsciousness/>.

Smith, P. F. (2012). Interactions between the vestibular nucleus and the dorsal cochlear nucleus: implications for tinnitus. Hearing Research, 292(1-2), 80-82. http://doi.org/10.1016/j.heares.2012.08.006

Sohmer, H., \& Freeman, S. (2001). The latency of auditory nerve brainstem evoked responses to air-and bone-conducted stimuli. Hearing Research.

Sohmer, H. (2017). Soft Tissue Conduction: Review, Mechanisms, and Implications. Trends in Hearing, 21, 2331216517734087. http://doi.org/10.1177/2331216517734087

Stager, S. V. (1990). Heterogeneity in stuttering. Journal of Fluency Disorders, 15(1), 9-19. http://doi.org/10.1016/0094-730X(90)90028-Q

Steinbeis, N. (2016). The role of self-other distinction in understanding others' mental and emotional states: neurocognitive mechanisms in children and adults. Phil. Trans. R. Soc. B, 371:20150074 http://doi.org/10.1098/rstb.2015.0074

Starkweather, C. W. \& Gottwald, S. R., (1990). The demands and capacities model: II. Clinical applications. Journal of Fluency Disorders, 15, 143-157.

Starkweather, C. W. (2002). The epigenesis of stuttering. Journal of Fluency Disorders, 27(4), 269-87quiz 287-8. http://doi.org/10.1016/s0094-730x(02)00144-4

Stevens, S.S. (1972) Perceived level of noise by mark VII and decibels (E). J Acoust Soc Am 51:575-601. Stromsta, C. (1972). Interaural phase disparity of stutterers and nonstutterers. Journal of Speech and Hearing Research, 15(4), 771-780. 
Stuart, A., Kalinowski, J., Rastatter, M., Saltuklaroglu, T., \& Dayalu, V. (2004). Investigations of the impact of altered auditory feedback in-the-ear devices on the speech of people who stutter: initial fitting and 4-month follow-up. International Journal of Language \& Communication Disorders, 39(1), 93-113. http://doi.org/10.1080/13682820310001616976

Suchodoletz, W., \& Wolfram, I. (1996). Brainstem auditory evoked potentials (BAEP) in children with developmental language disorders. Klinische Pädiatrie, 208(05), 290-293. http://doi.org/10.1055/s$\underline{2008-1046485}$

Sugathan, N., \& Maruthy, S. (2020). Predictive factors for persistence and recovery of stuttering in children: A systematic review. International Journal of Speech-Language Pathology, 1-13. http://doi.org/10.1080/17549507.2020.1812718

Suthers, R.A., Tecumseh Fitch, W., Fay, R.R. \& Popper, A.N. (eds) (2016) Vertebrate Sound Production and Acoustic Communication. Springer Handbook of Auditory Research, vol 53. Springer, New York, NY

Tahaei, A. A., Ashayeri, H., Pourbakht, A., \& Kamali, M. (2014). Speech evoked auditory brainstem response in stuttering. Scientifica, 2014, 328646. http://doi.org/10.1155/2014/328646

Theys, C., van Wieringen, A., Tuyls, L., \& De Nil, L. (2009). Acquired stuttering in a 16-year-old boy. Journal of Neurolinguistics, 22(5), 427-435. http://doi.org/10.1016/j.jneuroling.2009.02.001

Tichenor, S., \& Yaruss, J. S. (2018). A Phenomenological Analysis of the Experience of Stuttering. American Journal of Speech-Language Pathology, 27(3S), 1180-1194.

http://doi.org/10.1044/2018 AJSLP-ODC11-17-0192

Tichenor, S., \& Yaruss, J. S. (2019). Stuttering as Defined by Adults Who Stutter. Journal of Speech, Language and Hearing Research, vol 62, 4356-4369. http://doi.org/10.1044/2018 AJSLP-ODC11-17$\underline{0192}$

Todd, N. P. M., Paillard, A. C., Kluk, K., Whittle, E., \& Colebatch, J. G. (2014a). Vestibular receptors contribute to cortical auditory evoked potentials. Hearing Research, 309, 63-74. http://doi.org/10.1016/j.heares.2013.11.008

Todd, N. P. M., Paillard, A. C., Kluk, K., Whittle, E., \& Colebatch, J. G. (2014b). Source analysis of short and long latency vestibular-evoked potentials (VsEPs) produced by left vs. right ear air-conducted $500 \mathrm{~Hz}$ tone pips. Hearing Research, 312(C), 91-102. http://doi.org/10.1016/j.heares.2014.03.006

Todd, N. P. M., Rosengren, S. M., \& Colebatch, J. G. (2003). A short latency vestibular evoked potential (VsEP) produced by bone-conducted acoustic stimulation. Journal of the Acoustical Society of America, 114(6 Pt 1), 3264-3272. http://doi.org/10.1121/1.1628249

Todd, N.P.M., Rosengren, S.M., Colebatch, J.G., 2008. A source analysis of short- latency vestibular evoked potentials produced by air- and bone-conducted sound. Neurophysiol. Clin. 119 (8), $1881 \mathrm{e} 1894$.

Todd, N. P., \& Lee, C. S. (2015). The sensory-motor theory of rhythm and beat induction 20 years on: a new synthesis and future perspectives. Frontiers in Human Neuroscience, 9. http://doi.org/10.3389/fnhum.2015.00444

Toyomura A., Fujii T., Yokosawa K., \& Kuriki S. (2018). Speech disfluency-dependent amygdala activity in adults who stutter: Neuroimaging of interpersonal communication in MRI scanner environment. Neuroscience, 374, 144-154.

Toyomura, A., Koyama, S., Miyamaoto, T., Terao, A., Omori, T., Murohashi, H., \& Kuriki, S. (2007). Neural correlates of auditory feedback control in human. Neuroscience, 146(2), 499-503. https://doi.org/10.1016/j.neuroscience.2007.02.023

Traer, J., \& McDermott, J. H. (2016). Statistics of natural reverberation enable perceptual separation of sound and space. Proceedings of the National Academy of Sciences, 113(48), E7856-E7865. http://doi.org/10.1073/pnas.1612524113

Tye, M. (2018). "Qualia", The Stanford Encyclopedia of Philosophy (Summer 2018 Edition), Edward N. Zalta (ed.), URL $=<$ https://plato.stanford.edu/archives/sum2018/entries/qualia/>.

Van Borsel, J. (2014). Acquired stuttering: A note on terminology. Journal of Neurolinguistics, 27(1), 4149. http://doi.org/10.1016/j.jneuroling.2013.09.003

Van Riper, C. (1971), The Nature of Stuttering, 1st ed, Englewood Cliffs: Prentice-Hall.

Van Riper, C. (1973), The Treatment of Stuttering, Englewood Cliffs: Prentice-Hall. 
Van Riper, C. (1982), The Nature of Stuttering, 2nd ed, Englewood Cliffs: Prentice-Hall.

Walden, T. A., Frankel, C. B., Buhr, A. P., Johnson, K. N., Conture, E. G., \& Karrass, J. M. (2012). Dual diathesis-stressor model of emotional and linguistic contributions to developmental stuttering. Journal of abnormal child psychology, 40(4), 633-644. https://doi.org/10.1007/s10802-011-9581-8

Wallach, H., Newman, E. B., \& Rosenzweig, M. R. (1949). "The precedence effect in sound localization," The American Journal of Psychology, 62, 315-336.

Ward, D. (2010). Sudden onset stuttering in an adult: Neurogenic and psychogenic perspectives. Journal of Neurolinguistics.

Warren, R. (1973). Quantification of Loudness. The American Journal of Psychology, 86(4), 807-825. doi:10.2307/1422087

Waters, F. \& Fernyhough, C. (2019). Auditory Hallucinations: Does a Continuum of Severity Entail Continuity in Mechanism? Schizophrenia Bulletin 45(4): 717-719.

Weintraub, D. M., Ramage, E. M., Sutton, G., Ringdahl, E., Boren, A., Pasinski, A. C., et al. (2012). Auditory stream segregation impairments in schizophrenia. Psychophysiology, 49(10), 1372-1383. http://doi.org/10.1111/j.1469-8986.2012.01457.x

Welgampola, M. S., Rosengren, S. M., Halmagyi, G. M., \& Colebatch, J. G. (2003). Vestibular activation by bone conducted sound. Journal of Neurology, Neurosurgery \& Psychiatry, 74(6), 771-778. http://doi.org/10.1136/innp.74.6.771

Wingate, M. E. (1986a). Adaptation, consistency and beyond. I. Limitations and contradictions. Journal of Fluency Disorders, 11(1), 1-36 http://dx.doi.org/10.1016/0094-730X(86)90002-1.

Wingate, M. E. (1986b). Adaptation, consistency and beyond. II. An integral account. Journal of Fluency Disorders, 11(1), 37-53 http://dx.doi.org/10.1016/0094-730X(86)90003-3.

Wingate, M.E. (1969). Sound and pattern in "artificial" fluency. Journal of Speech and Hearing Research 12: 677-86.

Wyneken, C. (1868). Über das Stottern und dessen Heilung. Zeitschrift für rationelle Medizin, 31, 1-29.

Wu, J. C., Maguire, G., Riley, G., Lee, A., Keator, D., \& Tang, C. (1997). Increased dopamine activity associated with stuttering. Clinical Neuroscience and Neuropsychology, 8, 767-770.

Yadav, M., Cabrera, D., \& Martens, W. L. (2012). A system for simulating room acoustical environments for one's own voice. Applied Acoustics, 73(4), 409-414. http://doi.org/10.1016/j.apacoust.2011.10.001

Yates, A. J. (1963). Recent Empirical and Theoretical Approaches to the Experimental Manipulation of Speech in Normal Subjects and in Stammerers. Behaviour Research and Therapy, 1(2-4), 95-119. http://doi.org/10.1016/0005-7967(63)90013-5

Yairi E. (2007) Subtyping Stuttering I: A Review. Journal of Fluency Disorders. 32(3):165-96. doi: 10.1016/j.jfludis.2007.04.001

Yairi, E., \& Ambrose, N. (2013). Epidemiology of stuttering: 21st century advances. Journal of Fluency Disorders, 38(2), 66-87. http://doi.org/10.1016/j.jfludis.2012.11.002

Yang, Y., Jia, F., Siok, W. T., \& Tan, L. H. (2017). The role of anxiety in stuttering: Evidence from functional connectivity. Neuroscience, 346, 216-225. http://doi.org/10.1016/j.neuroscience.2016.11.033

Yates, A. J. (1963). Recent Empirical and Theoretical Approaches to the Experimental Manipulation of Speech in Normal Subjects and in Stammerers. Behaviour Research and Therapy, 1(2-4), 95-119. http://doi.org/10.1016/0005-7967(63)90013-5

Zarate, J. M., Wood, S., \& Zatorre, R. J. (2010). Neural networks involved in voluntary and involuntary vocal pitch regulation in experienced singers. Neuropsychologia, 48(2), 607-618. https:// doi.org/10.1016/j.neuropsychologia.2009.10.025

Zarate, J. M., \& Zatorre, R. J. (2008). Experience-dependent neural substrates involved in vocal pitch regulation during singing. Neurolmage, 40(4), 1871-1887. https://doi.org/10.1016/ j.neuroimage.2008.01.026

Zheng, Z. Z., Munhall, K. G., \& Johnsrude, I. S. (2009). Functional overlap between regions involved in speech perception and in monitoring one's own voice during speech production. Journal of Cognitive Neuroscience, 22(8), 1770-1781. https:// doi.org/10.1162/jocn.2009.21324

Zwergal, A., Strupp, M., Brandt, T., \& Büttner-Ennever, J. A. (2009). Parallel ascending vestibular pathways: anatomical localization and functional specialization. Annals of the New York Academy of Sciences, 1164(1), 51-59. http://doi.org/10.1111/j.1749-6632.2009.04461.x 
bioRxiv preprint doi: https://doi.org/10.1101/2020.11.24.396283; this version posted August 3, 2021. The copyright holder for this preprint

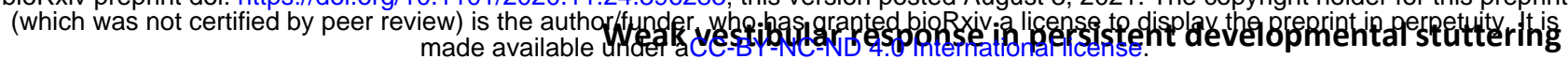
and implications for own voice identification 